\title{
The Competing Dehalogenation versus Borylation of Aryl Iodides and Bromides under Transition Metal-Free Basic Conditions
}

\author{
Yi-Jie Niu, ${ }^{\dagger \#}$ Guo-Hui Sui, ${ }^{\dagger \#}$ Hong-Xing Zheng, ${ }^{\ddagger}$ Xiang-Huan Shan, ${ }^{\S}$ Lin Tie, ${ }^{\S}$ Jia-Le Fu, ${ }^{\S}$ \\ Jian-Ping $\mathbf{Q u}^{\dagger *}$ and Yan-Biao Kang ${ }^{\S *}$ \\ $\dagger$ Institute of Advanced Synthesis, School of Chemistry and Molecular Engineering, Jiangsu National \\ Synergetic Innovation Center for Advanced Materials, Nanjing Tech University, Nanjing 211816, China, \\ ias_jpqu@njtech.edu.cn \\ $\$$ School of Chemistry and Chemical Engineering, Liaocheng University, Liaocheng, Shandong 252059, \\ China \\ $\S$ Department of Chemistry, University of Science and Technology of China, Hefei, Anhui 230026, \\ China, ybkang@ustc.edu.cn
}

Table of Contents

NMR spectra

S2-47 
NMR spectra

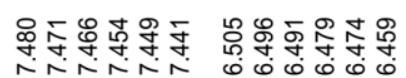

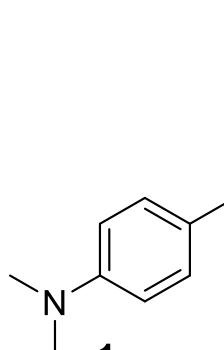

$1 \mathrm{e}$

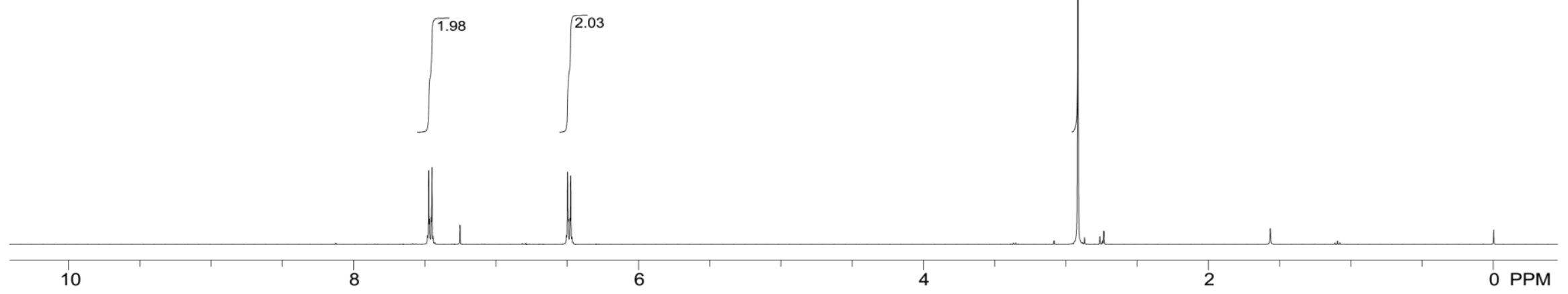




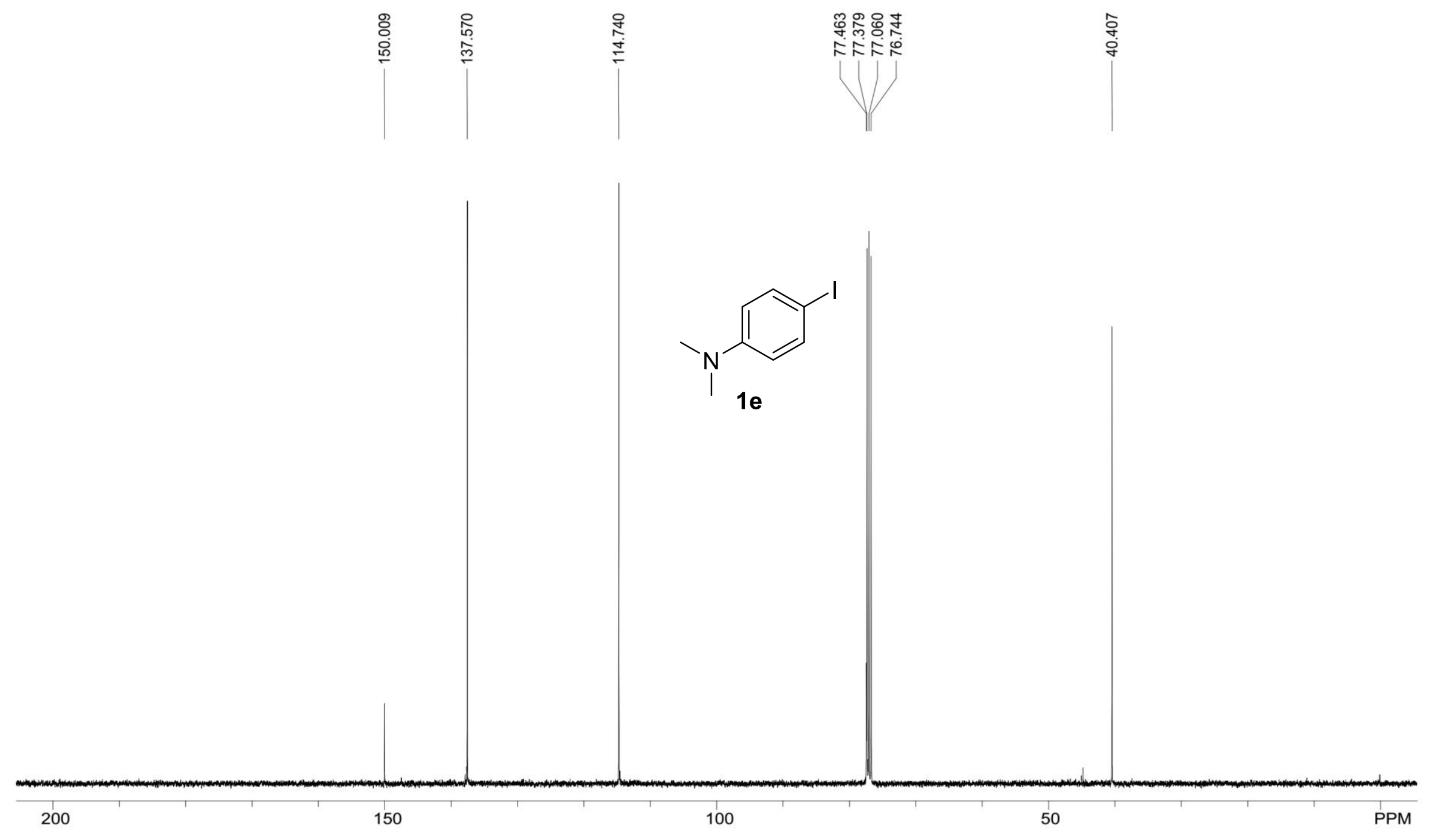



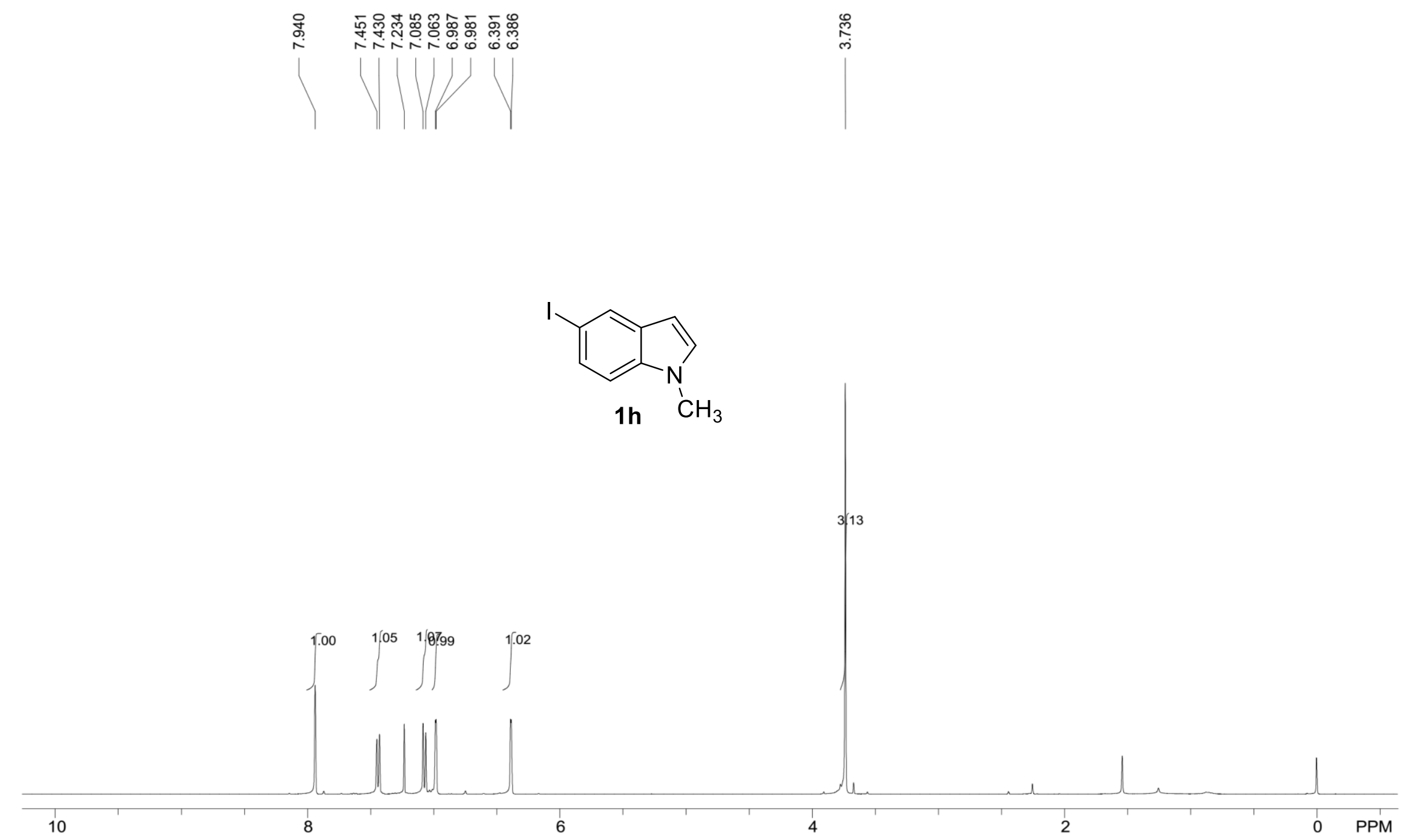

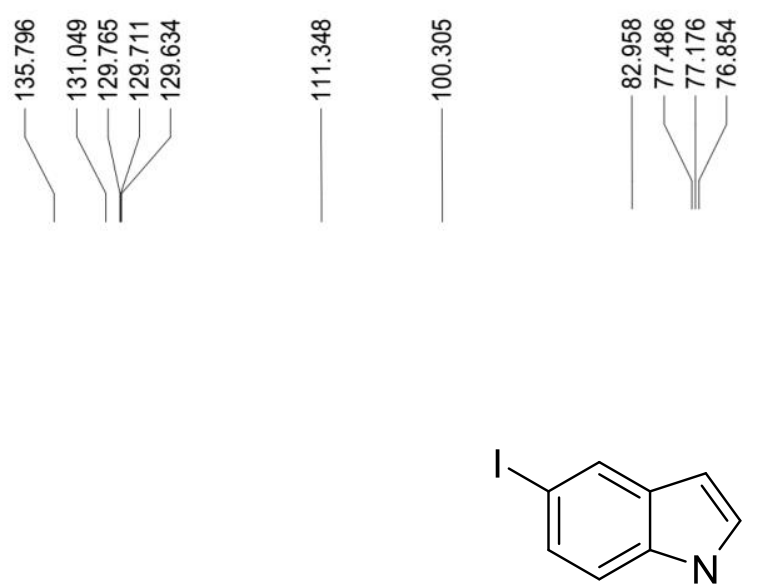

1h $\mathrm{CH}_{3}$

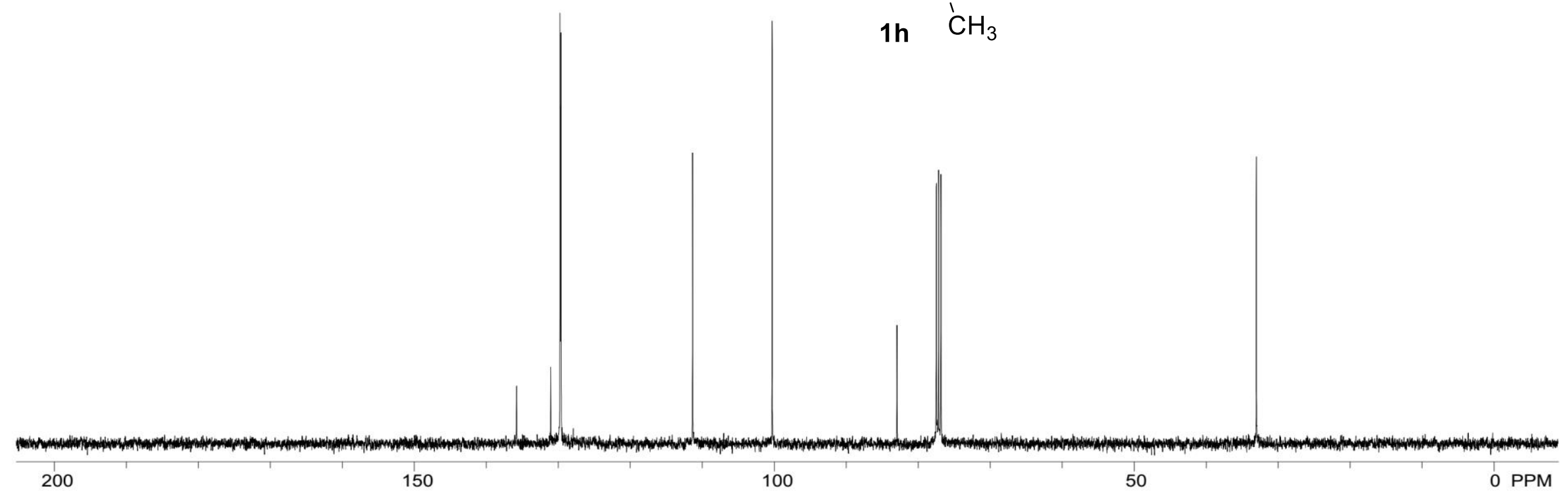




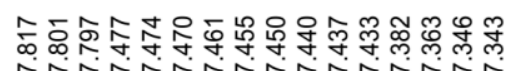

LULUUUJJJJJ

I lif

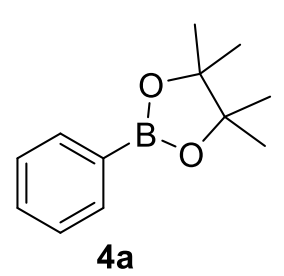

T.99 2.03

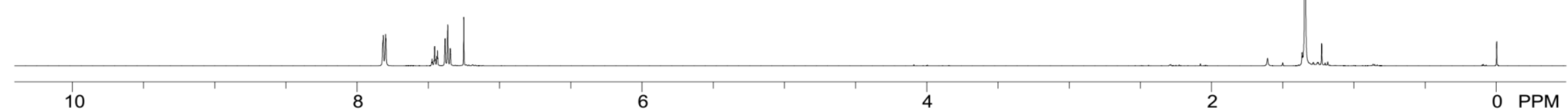



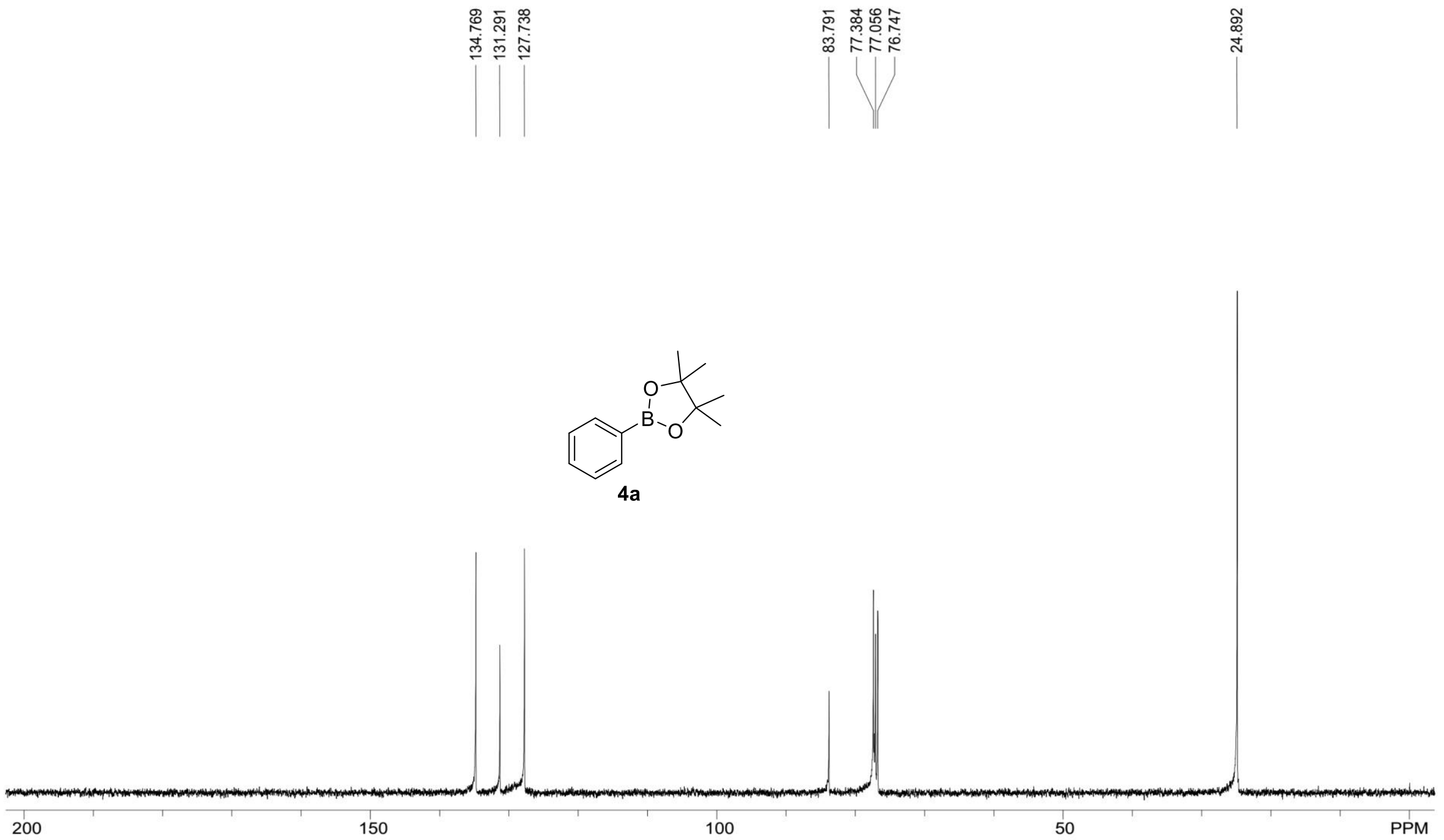


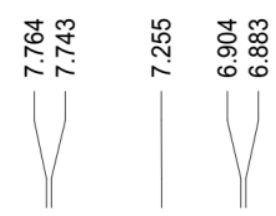

$\bar{\infty}$

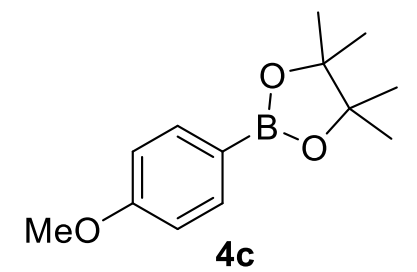

3.08

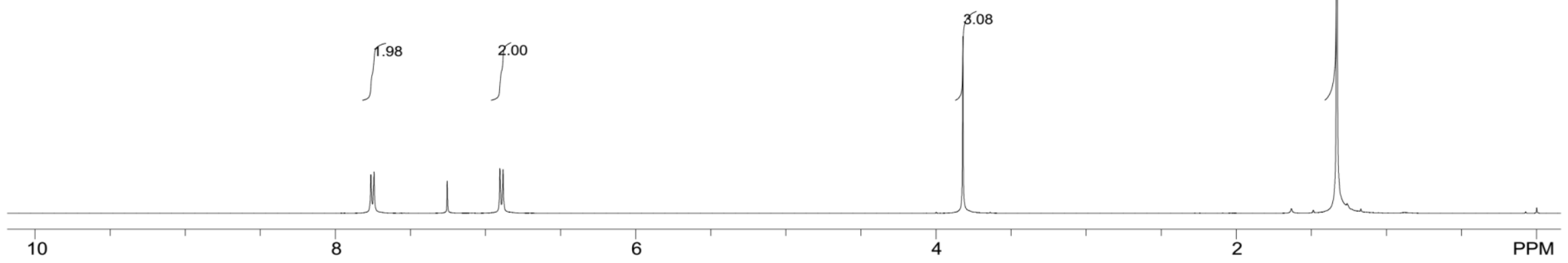




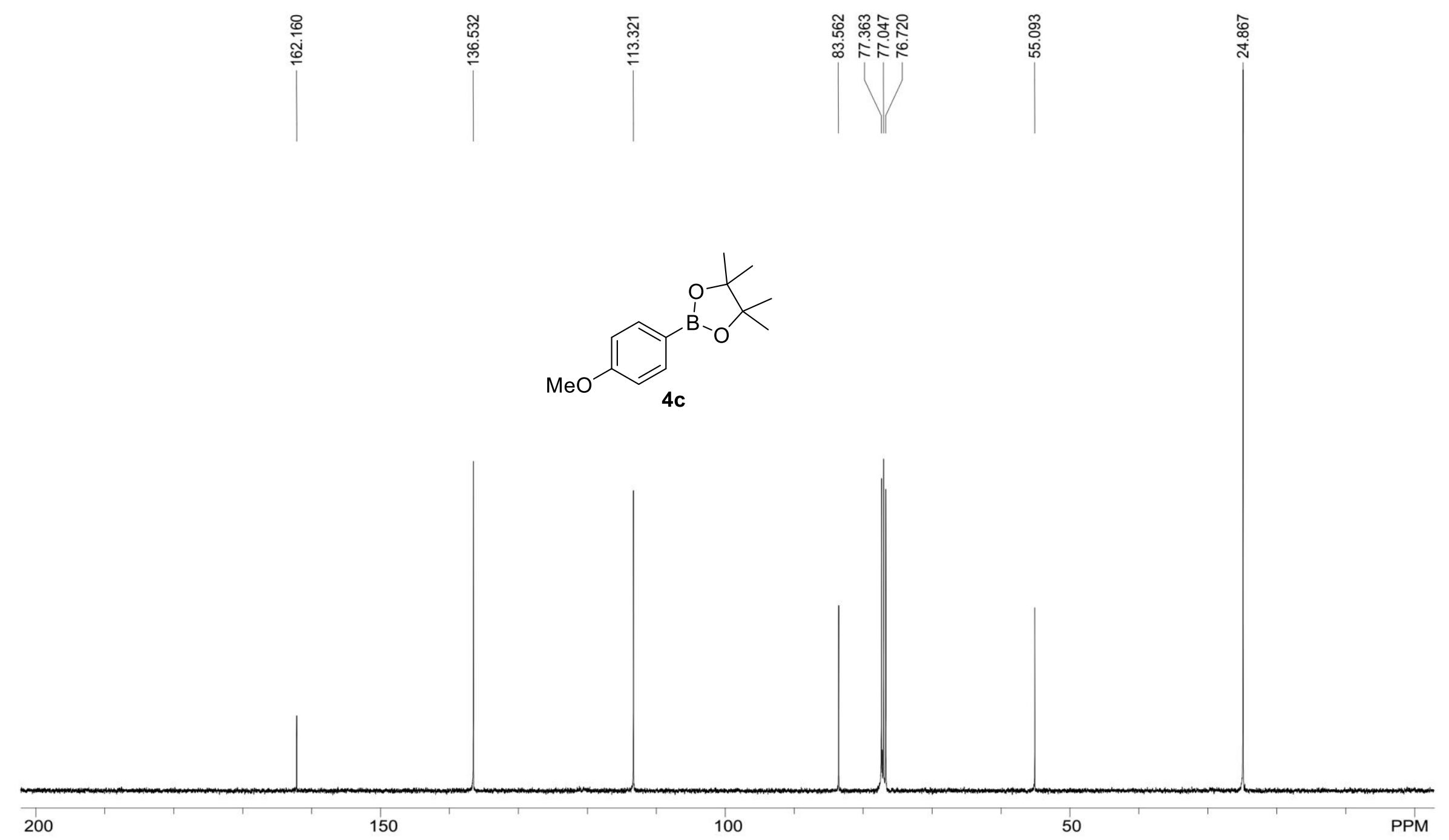



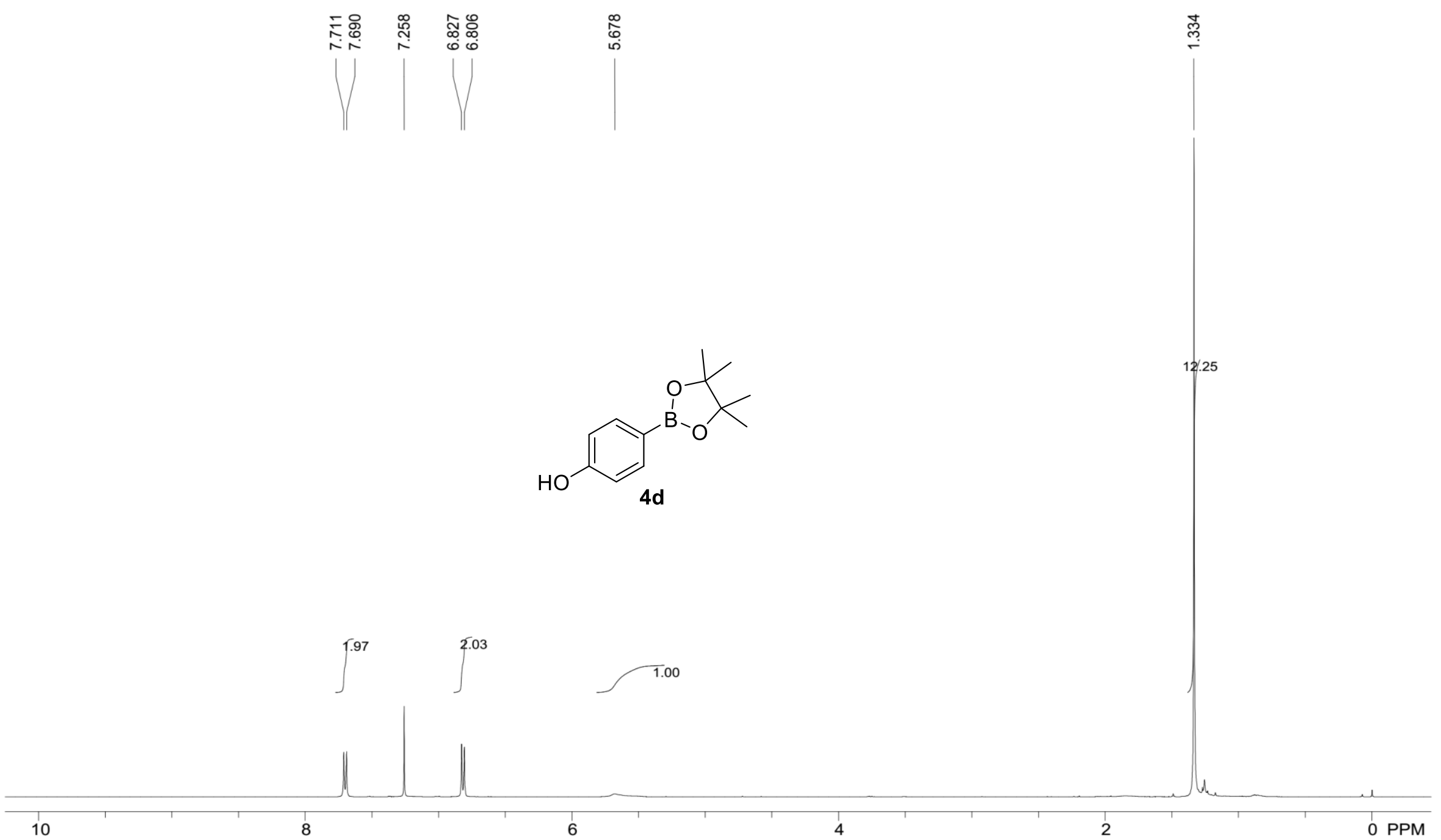

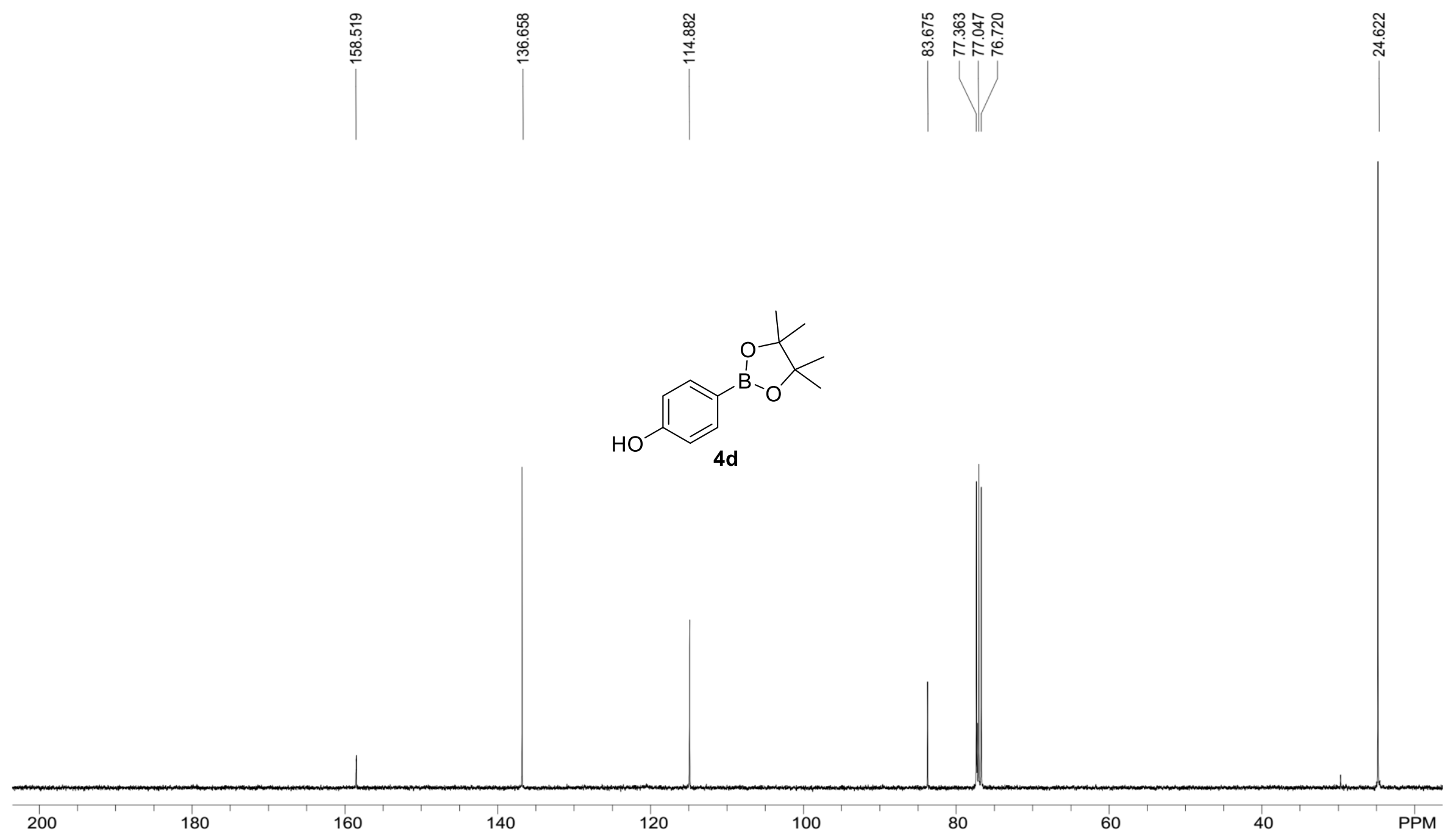


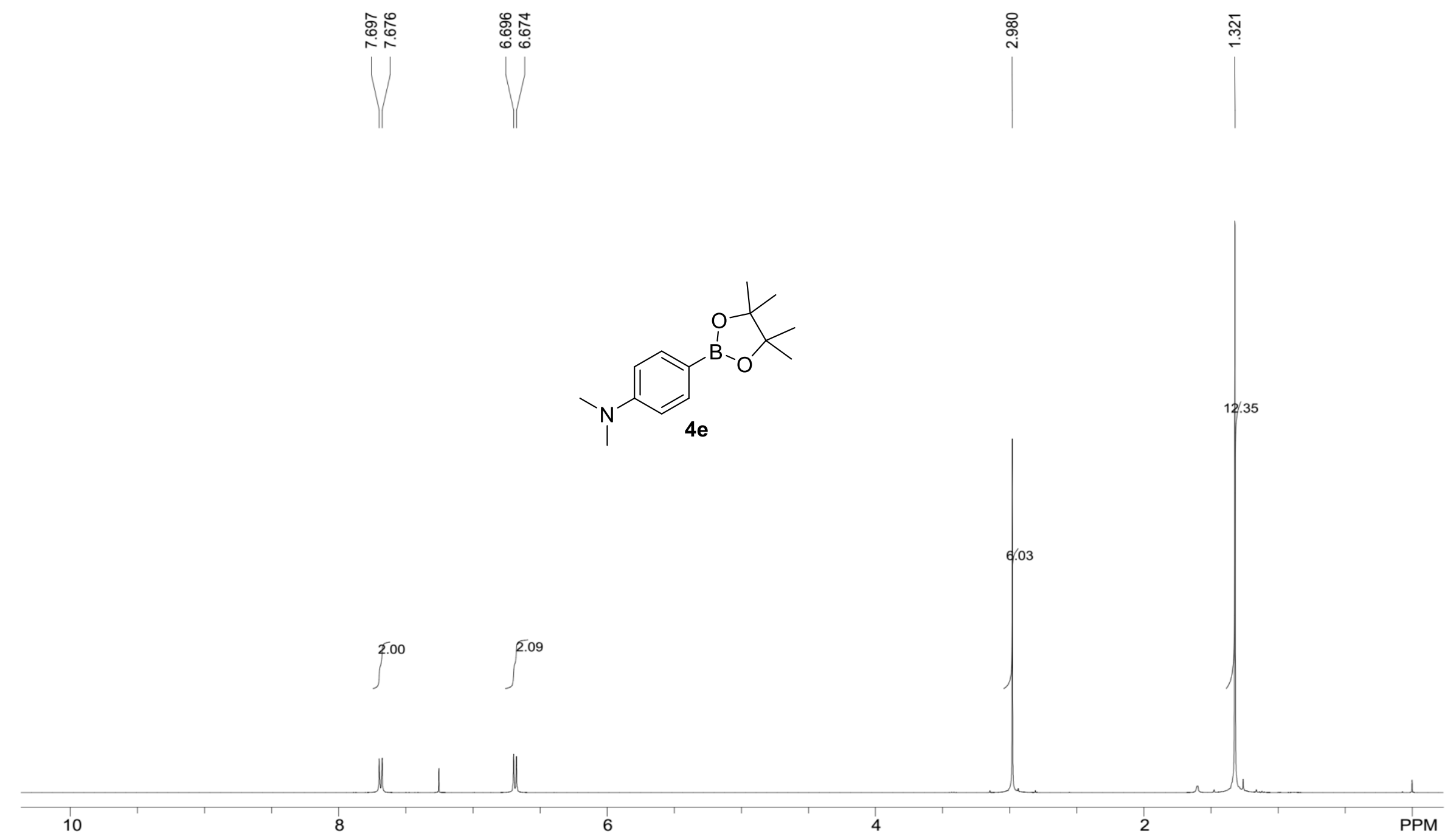




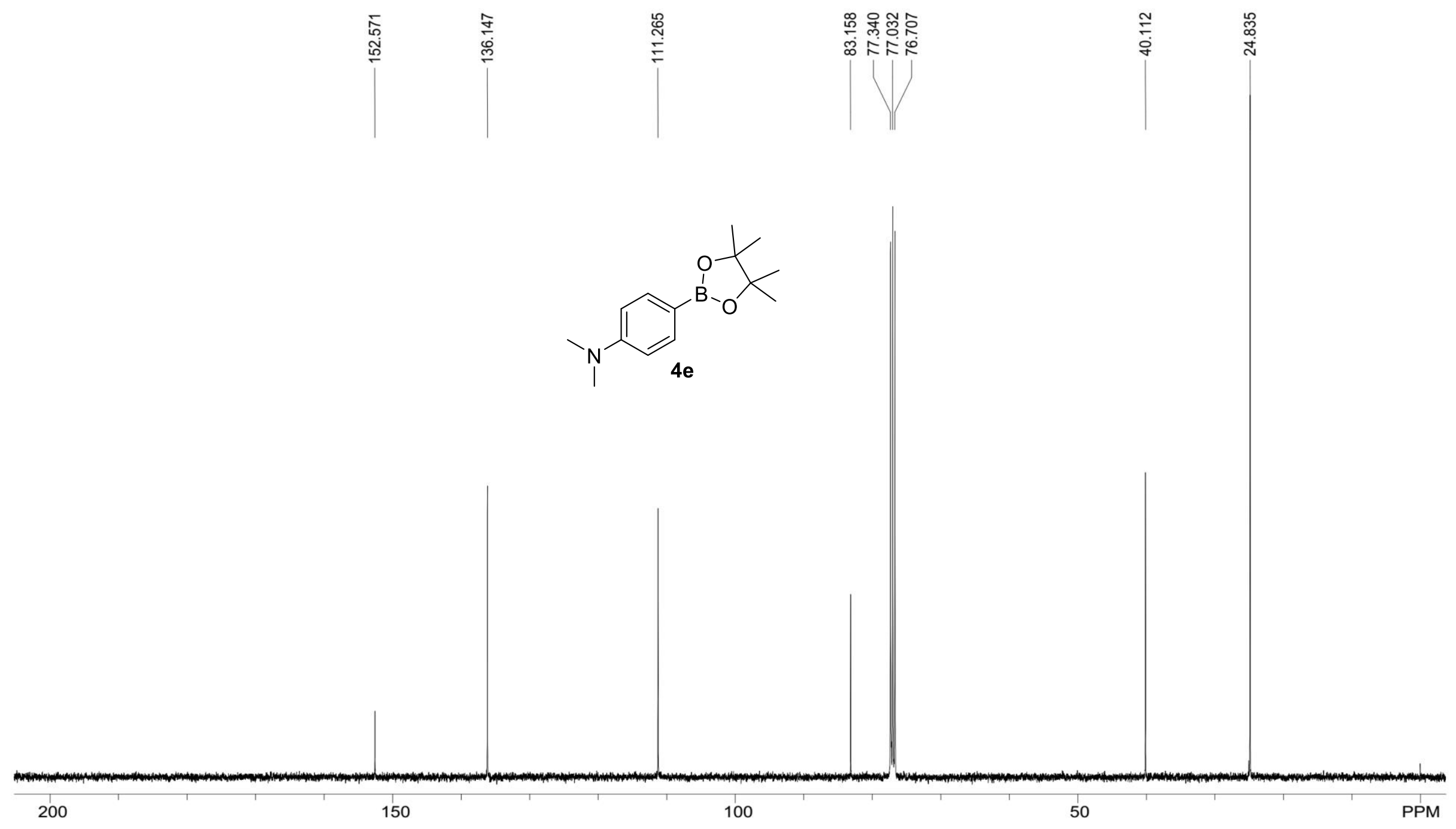




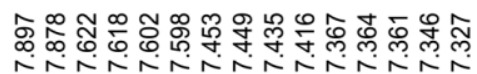
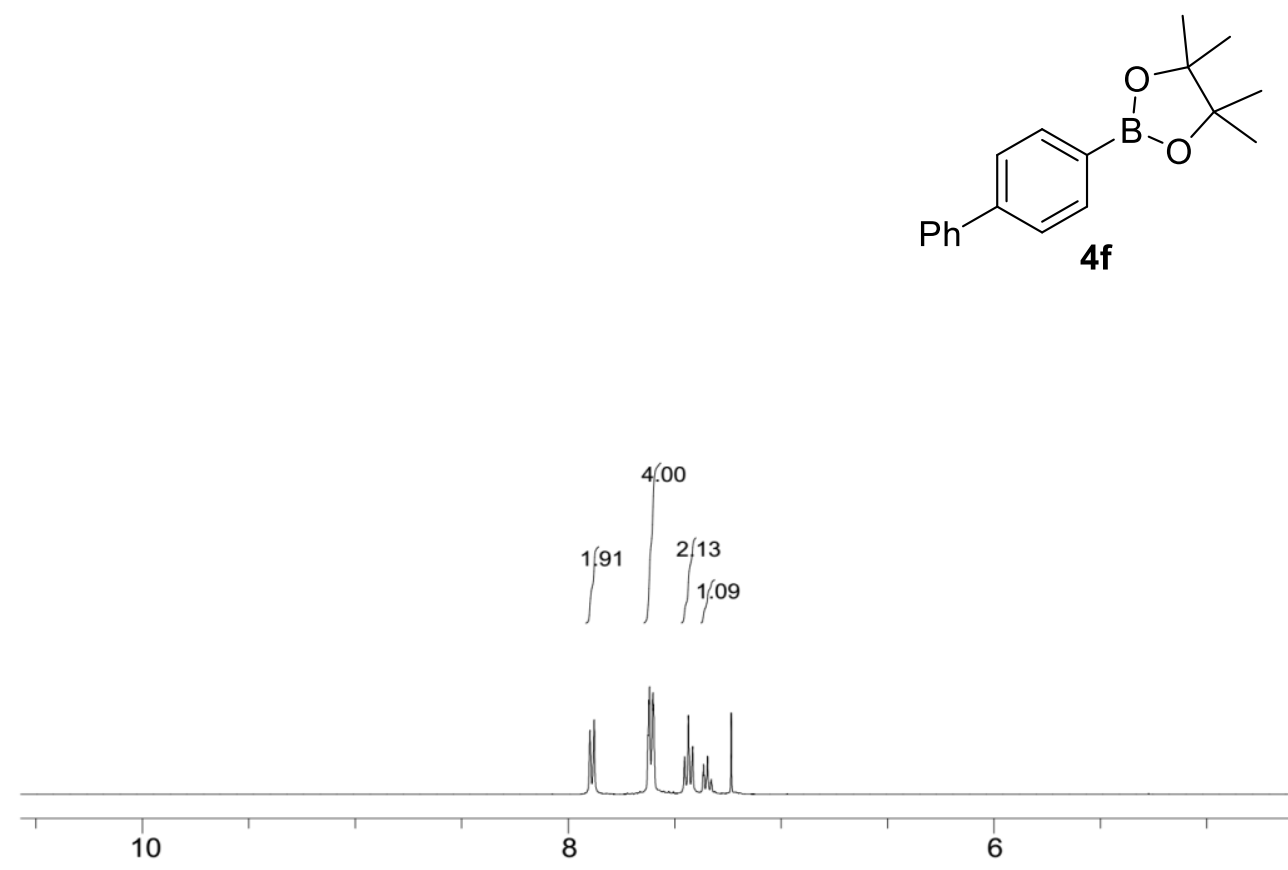

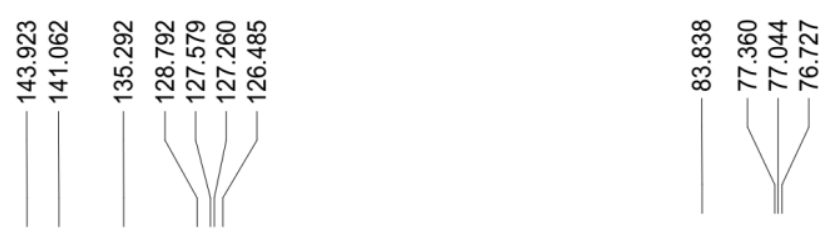

8
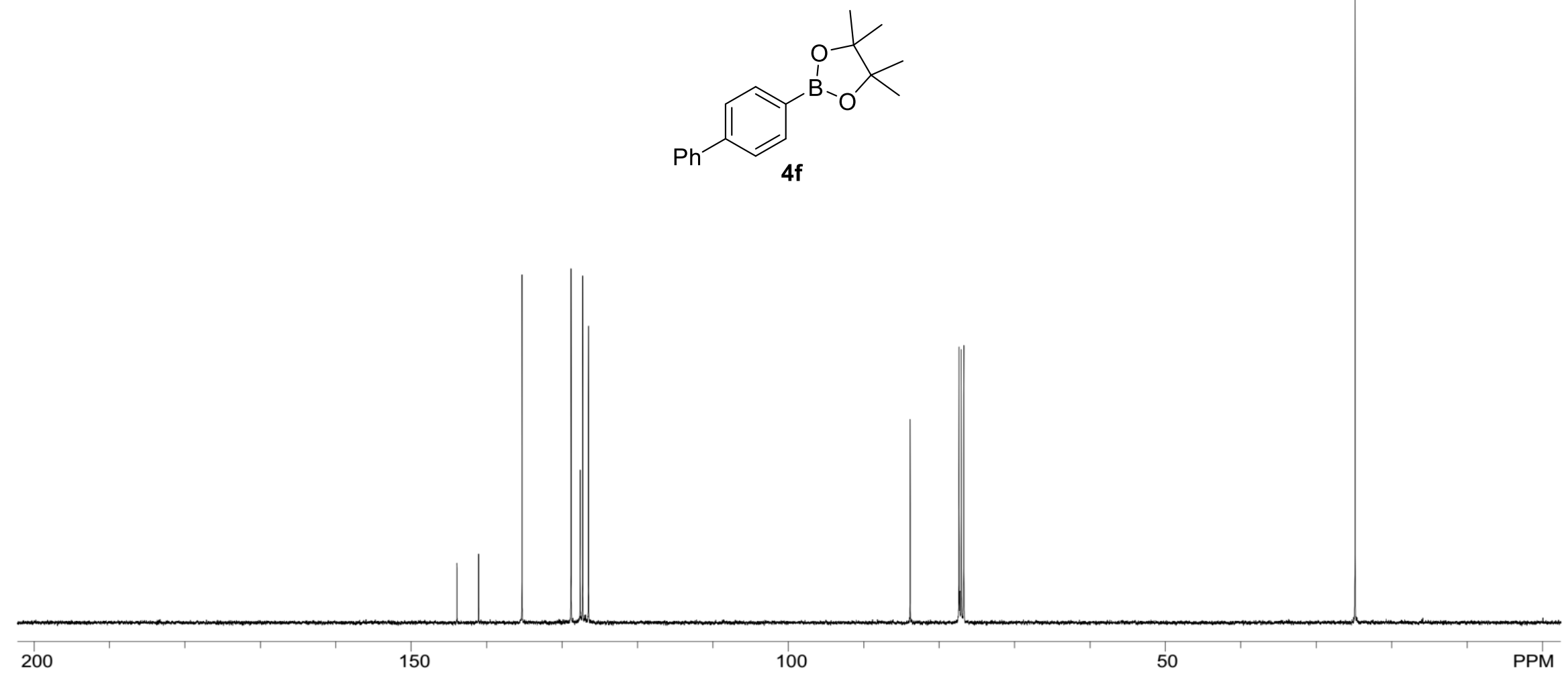

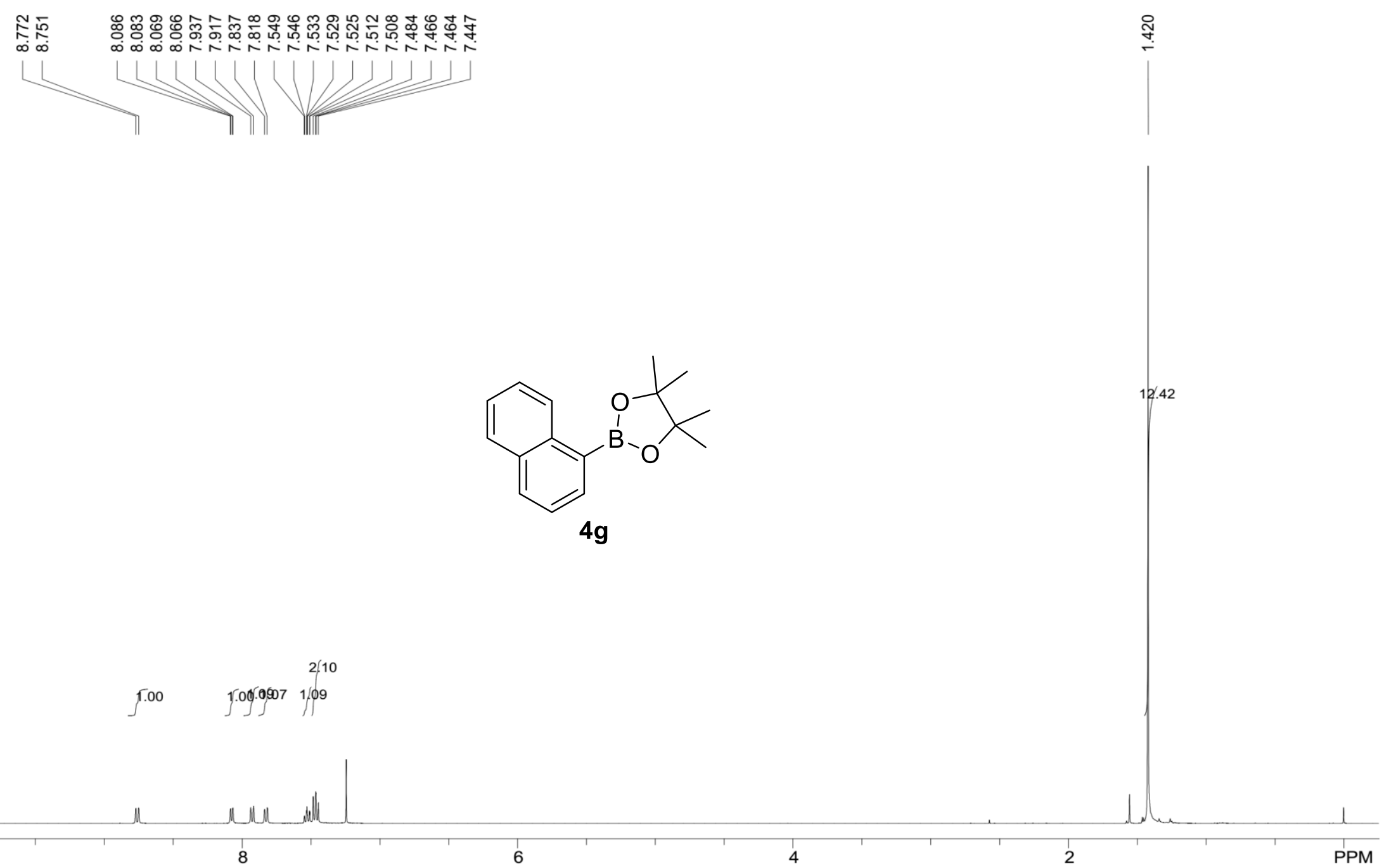

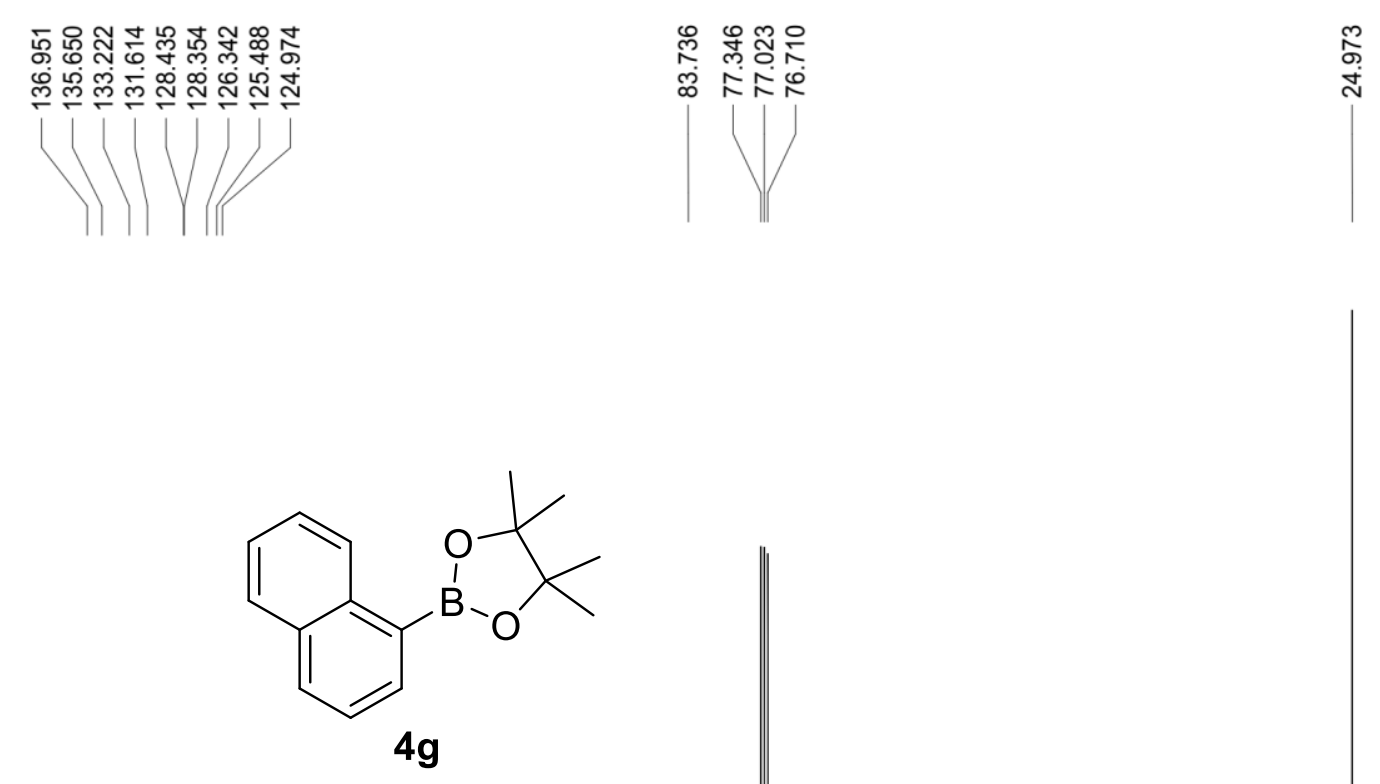


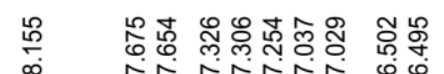

$\underset{\substack{\infty \\ \hdashline}}{\infty}$
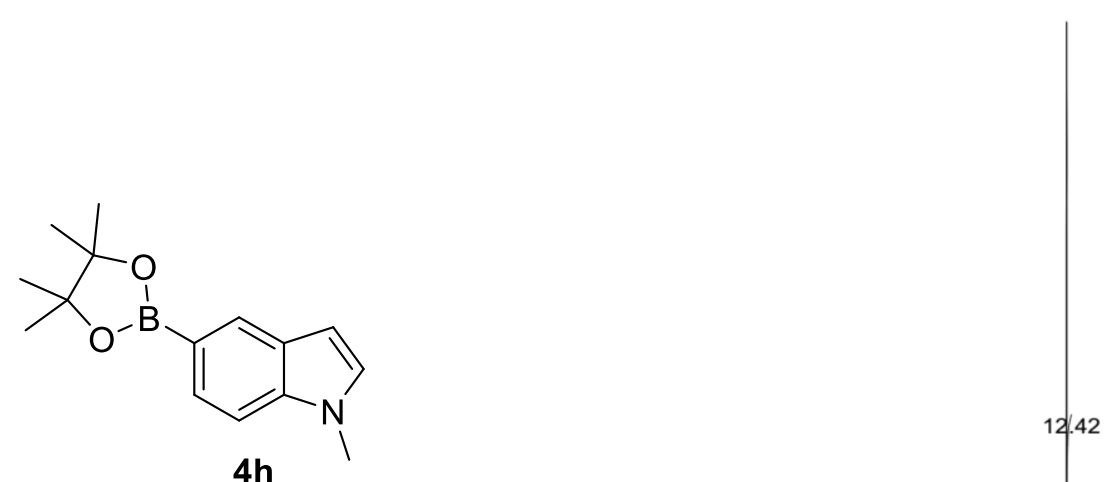

$0.98 \quad 1.02 \quad 1.05 \quad 1.00$

T.02

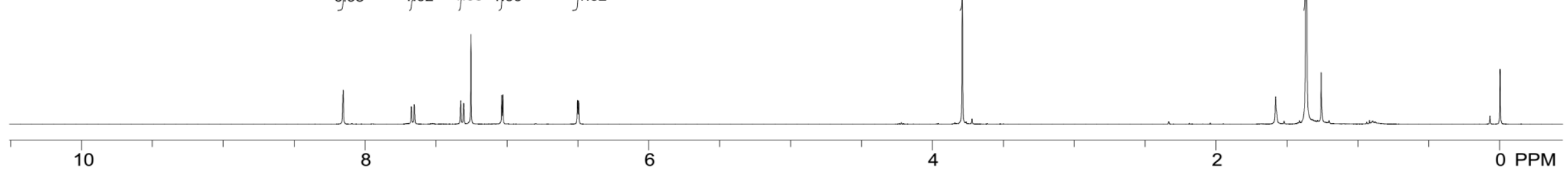



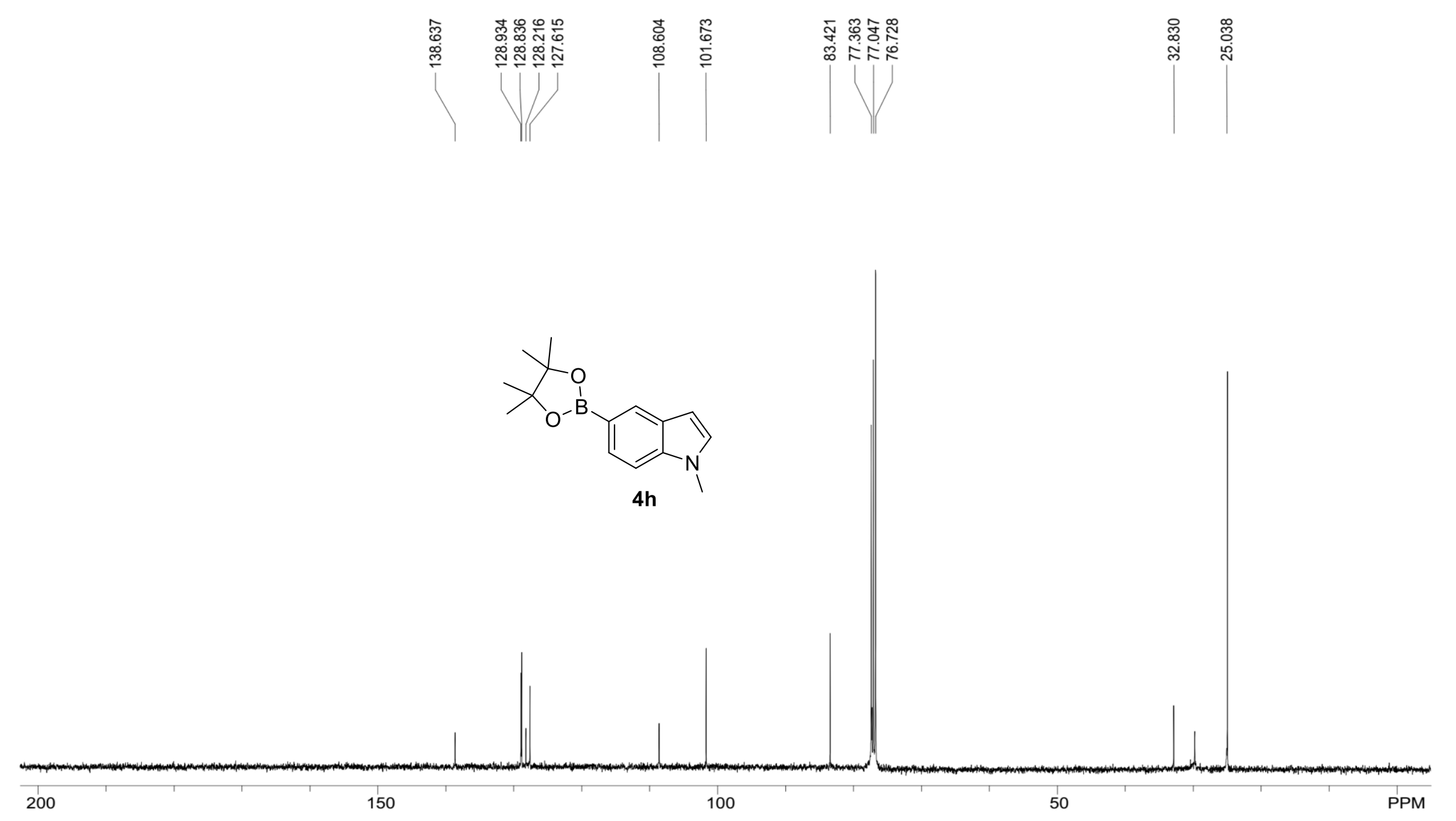


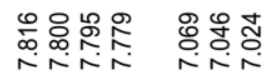

$\stackrel{\text { mo }}{\stackrel{\text { }}{\circ}}$

H
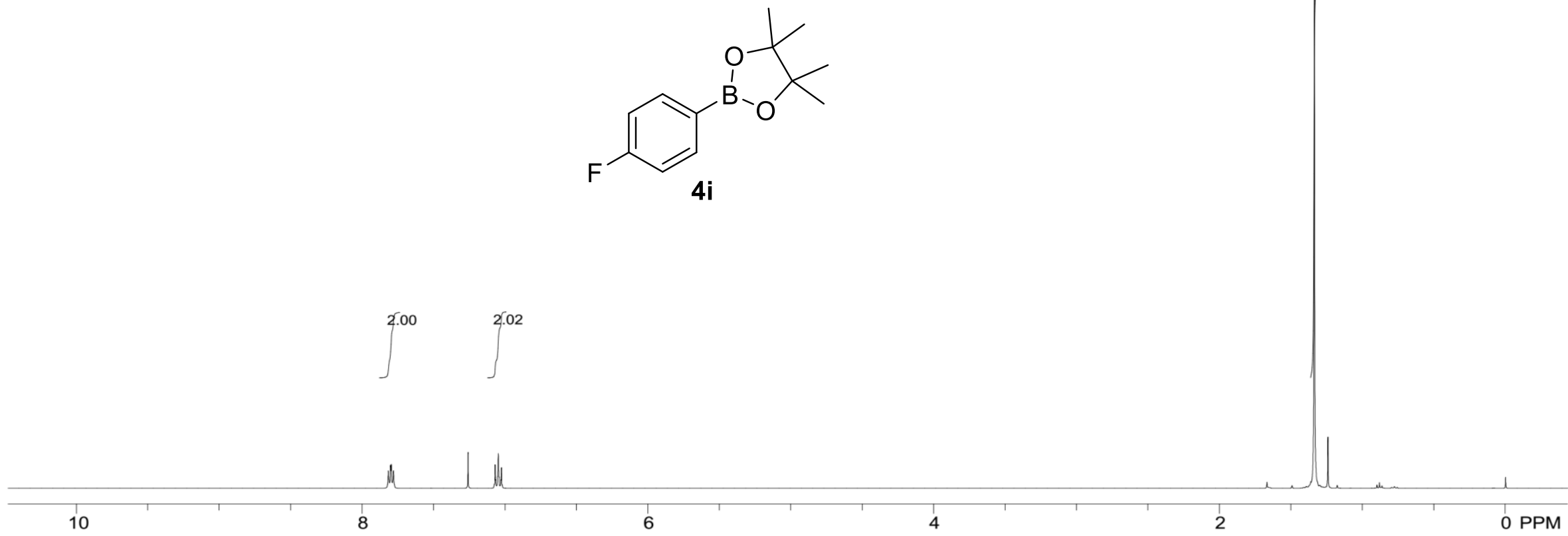

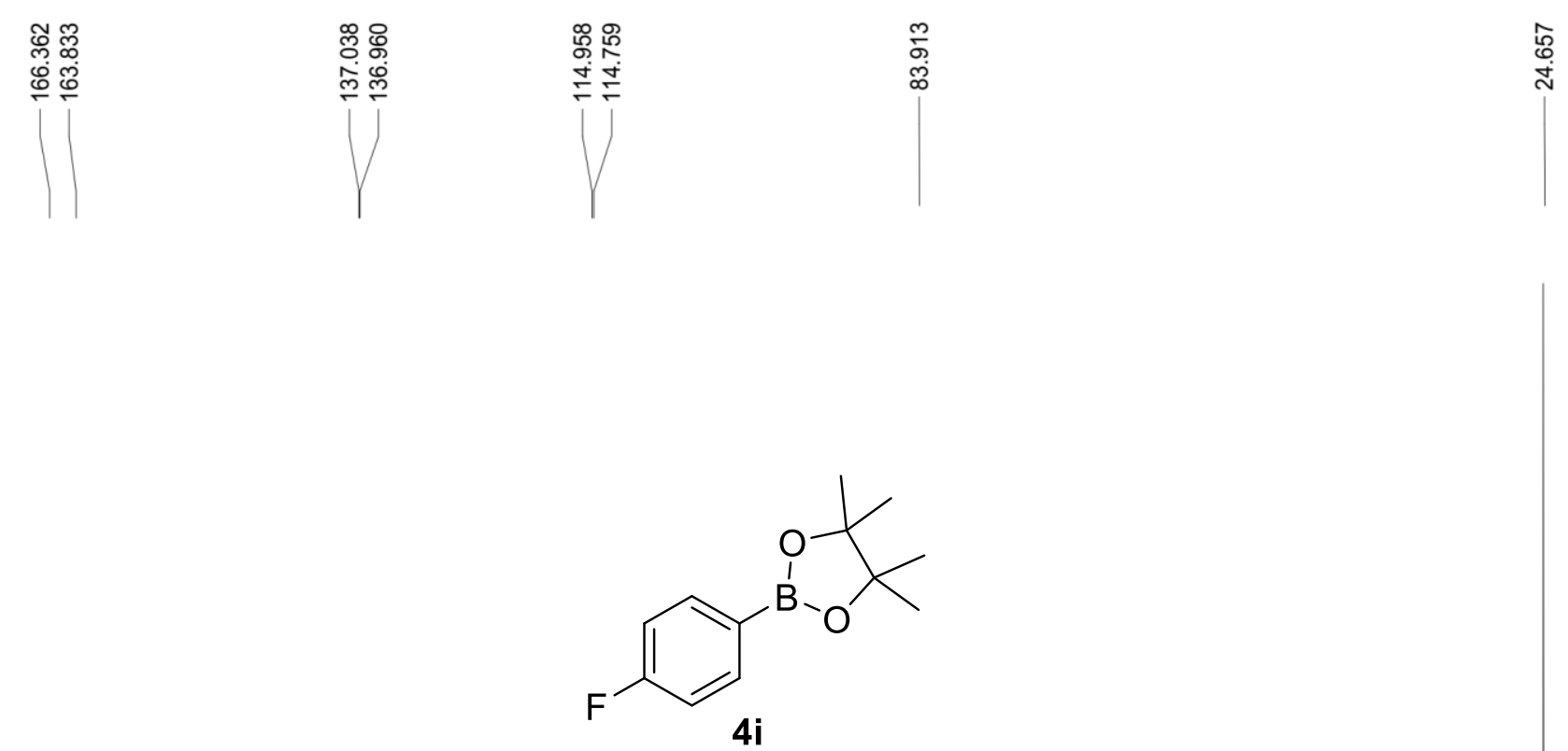


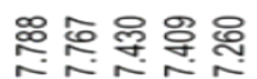

il

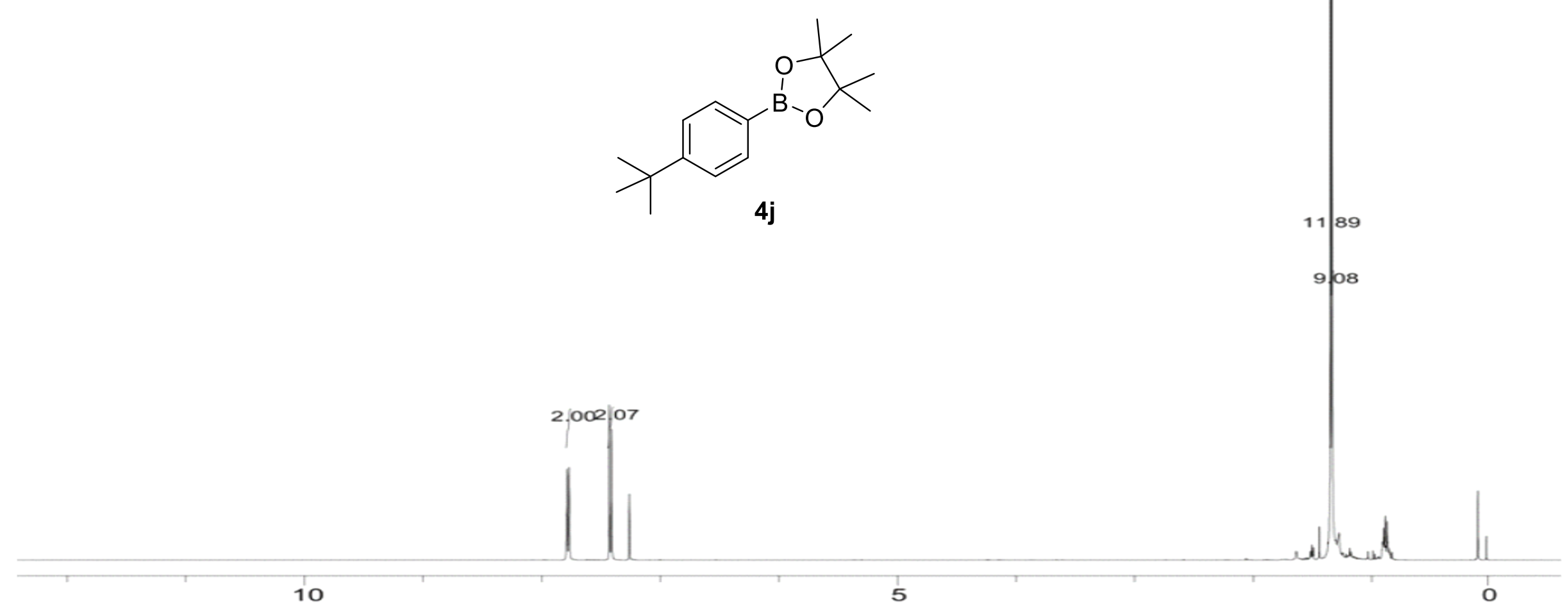

㐘皮 

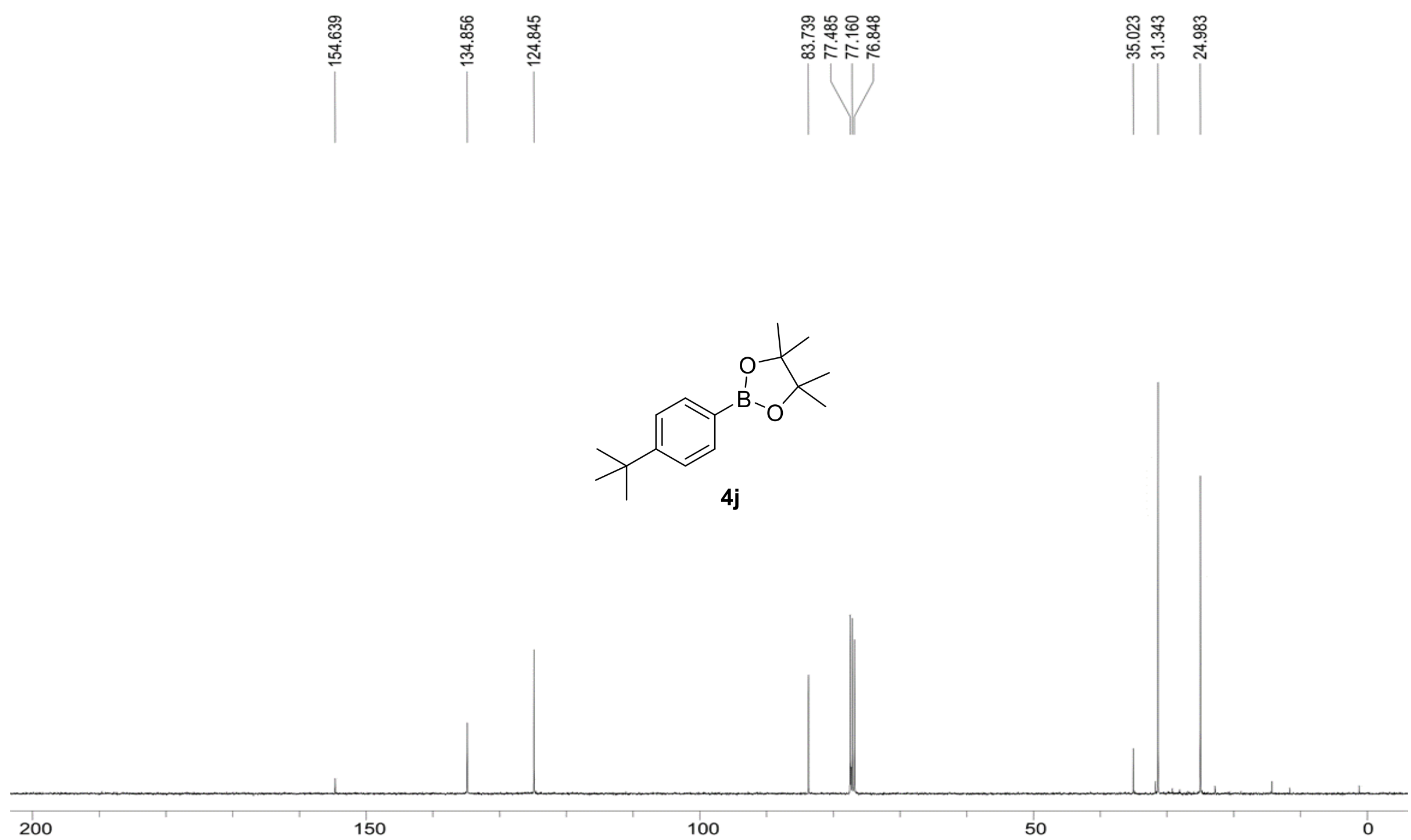


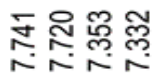

Viv

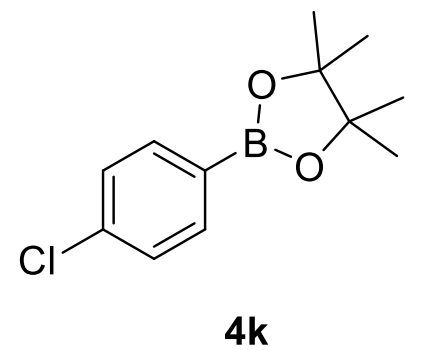

$2.00 \quad 2.00$

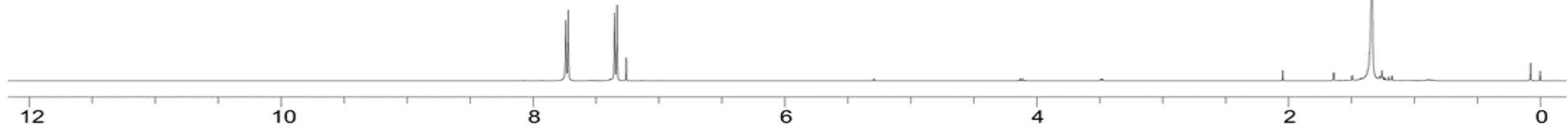




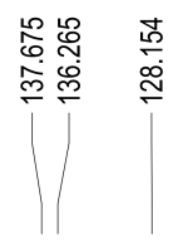

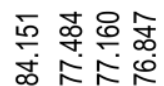

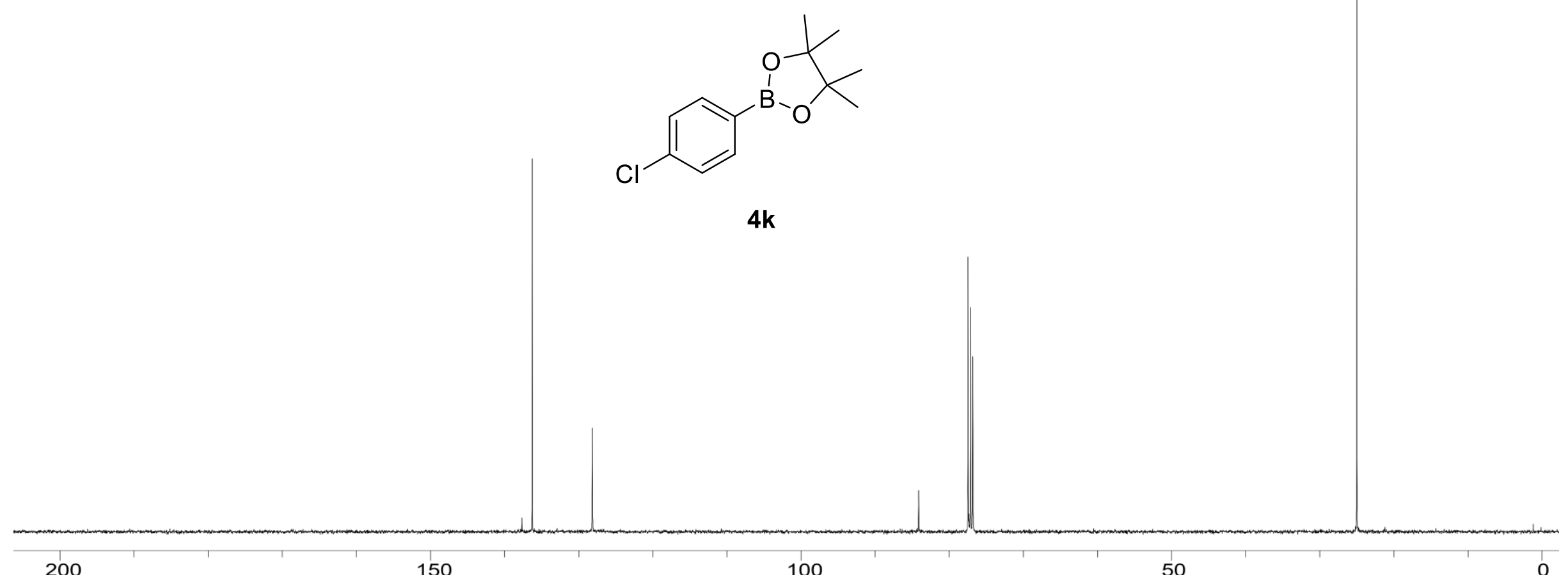



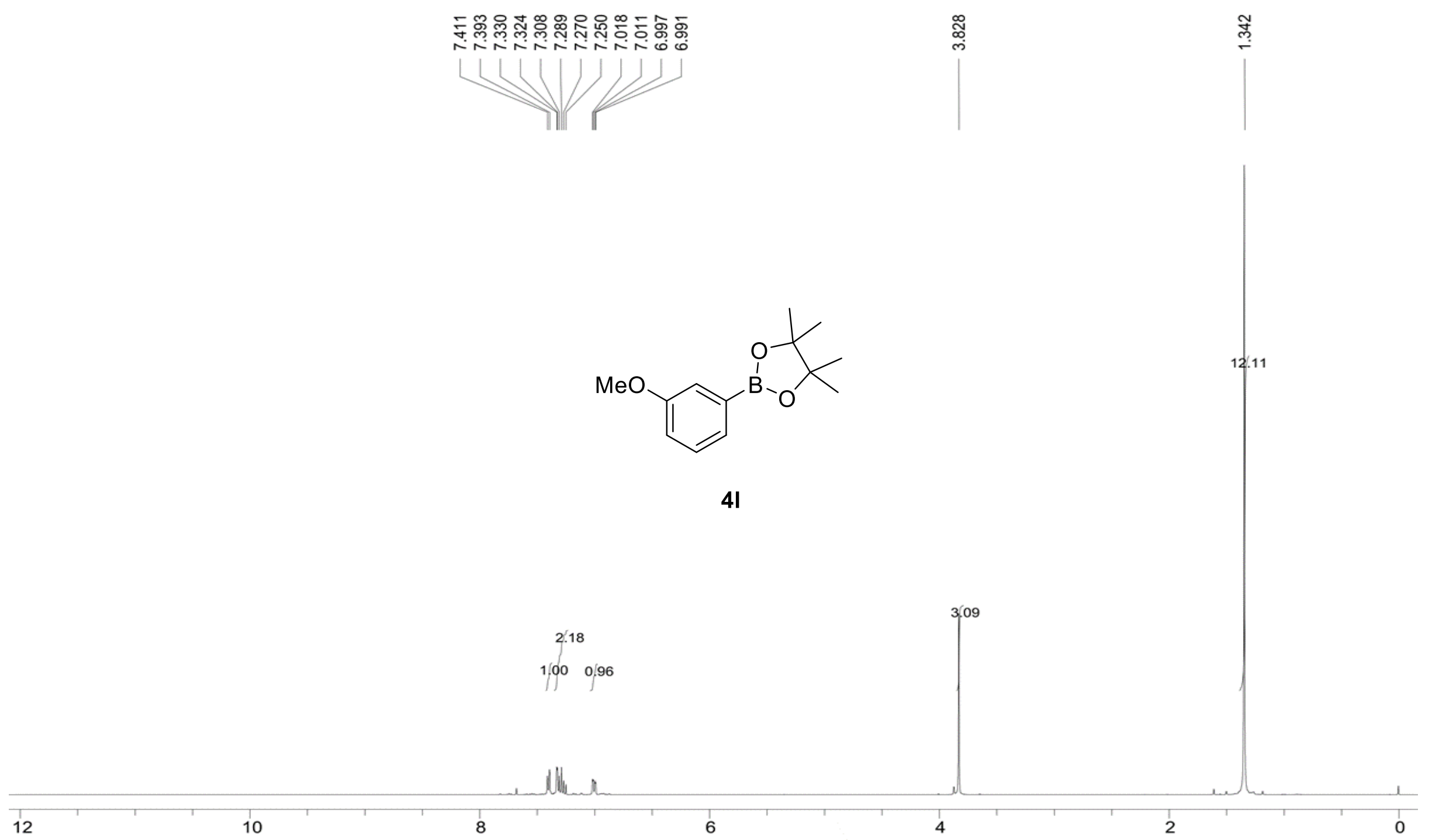

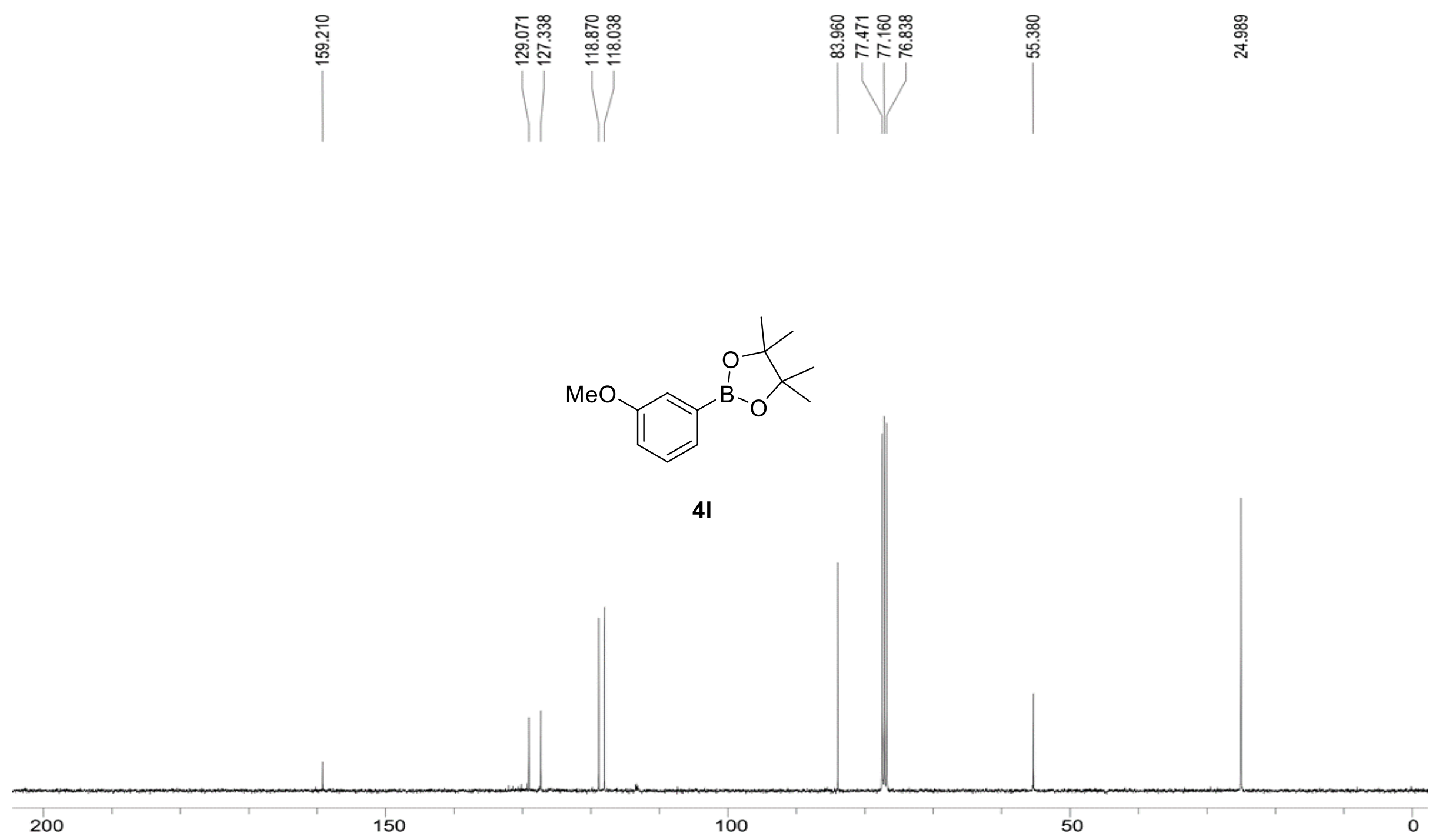


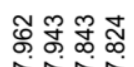

善㗐

UV

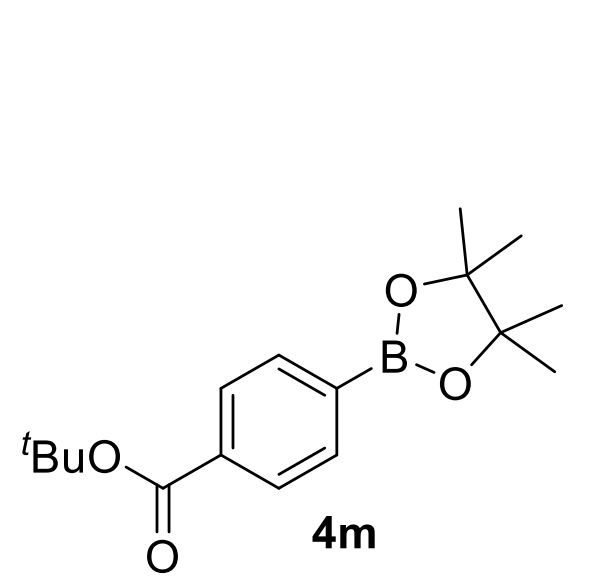

2.000
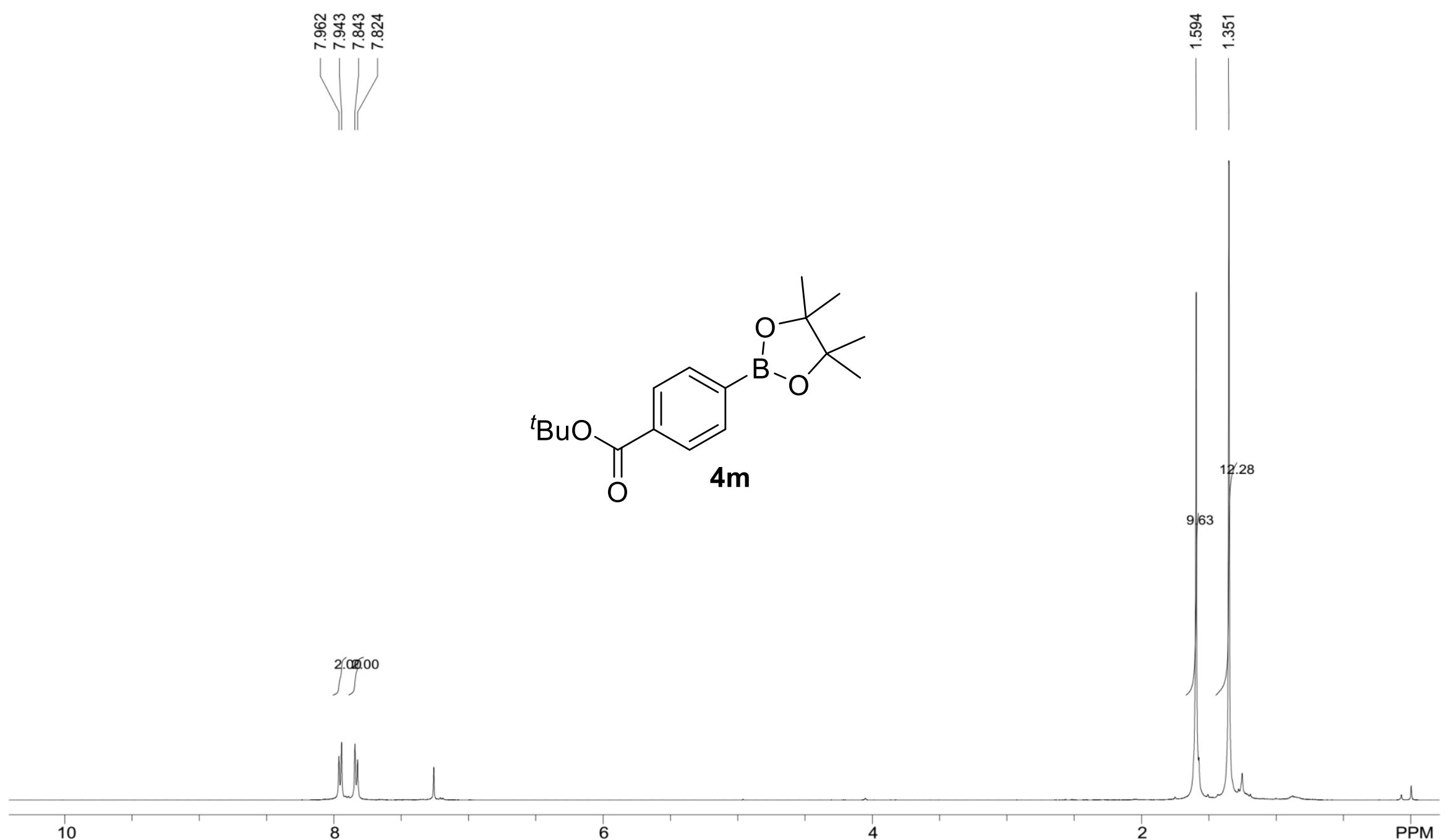

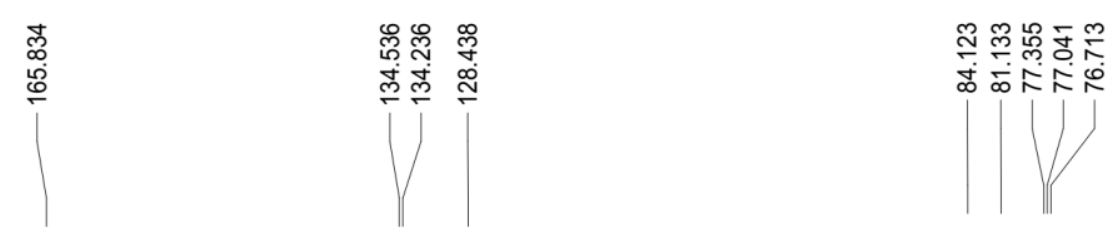

๓๐

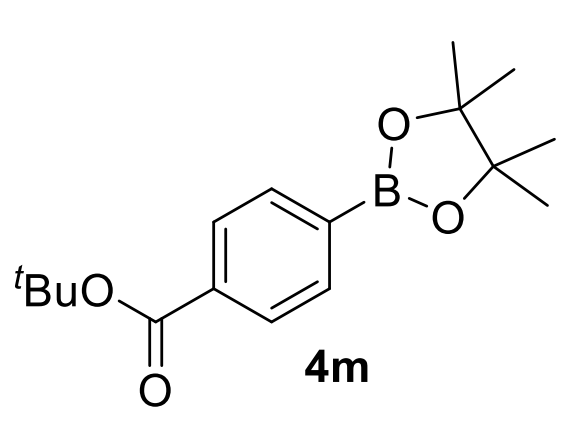




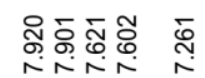

il

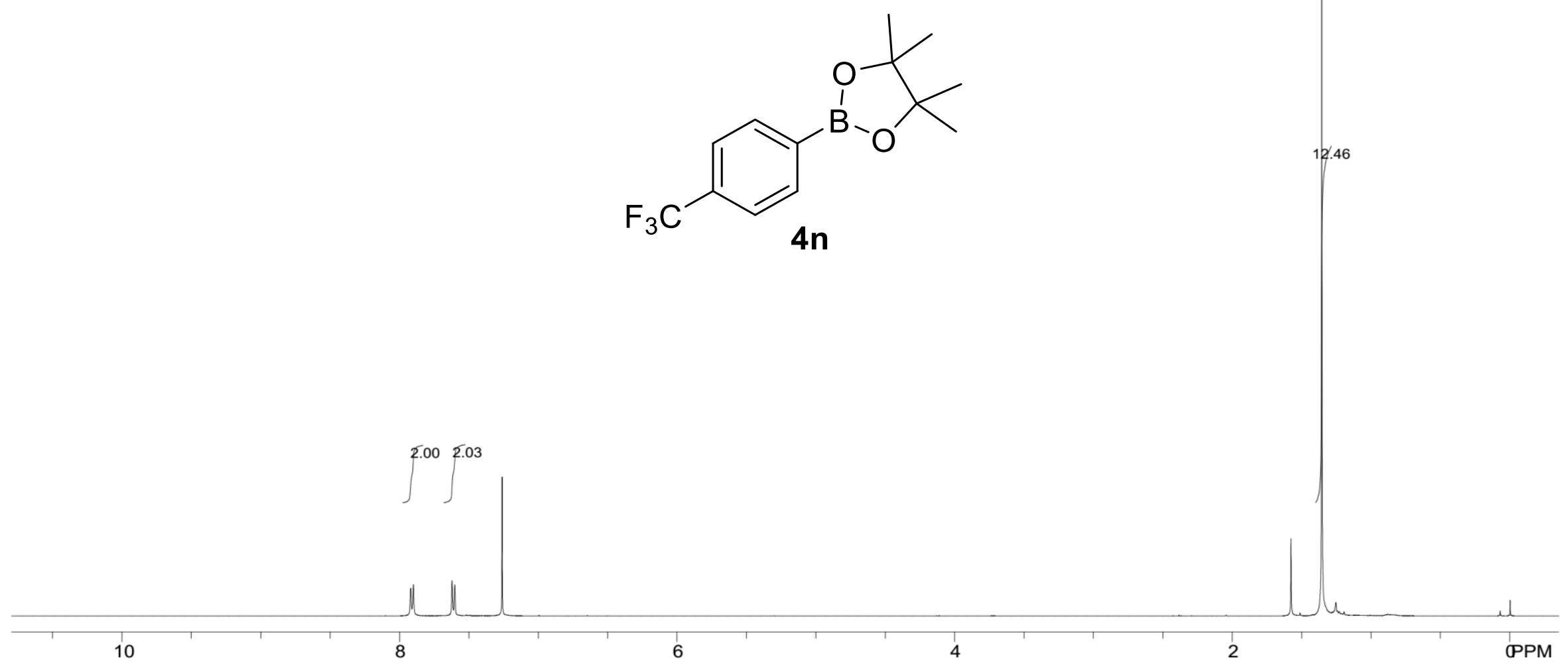




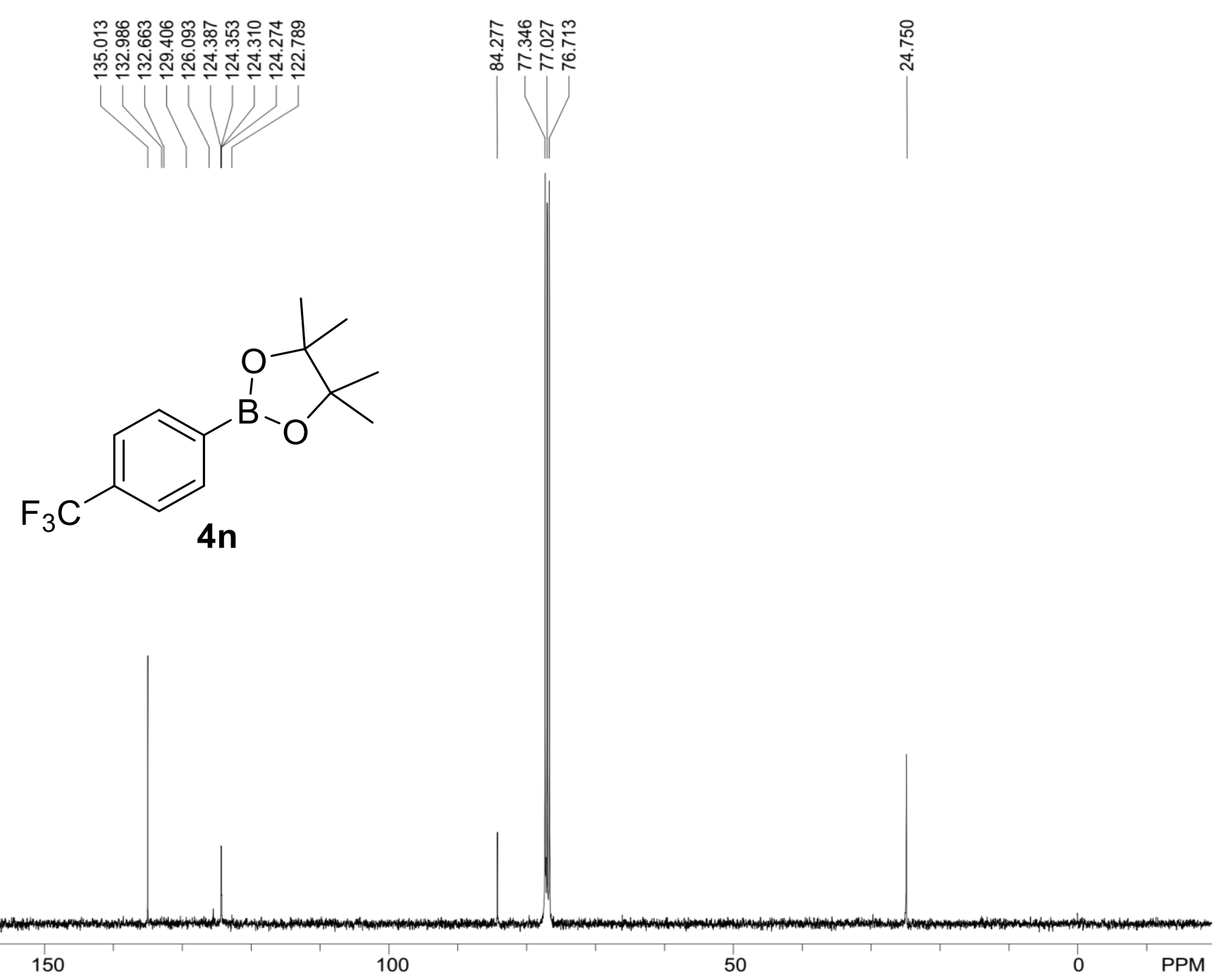



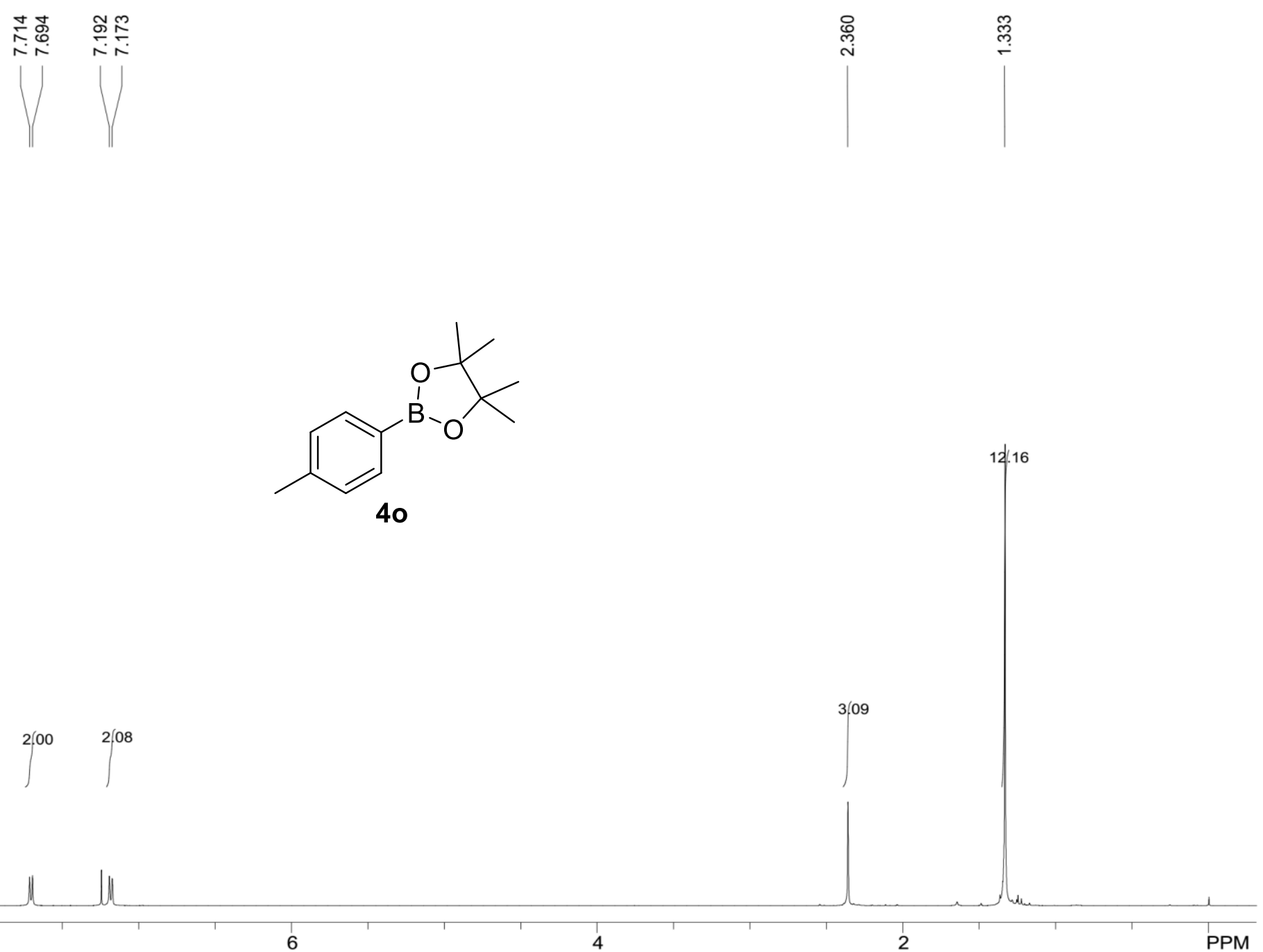

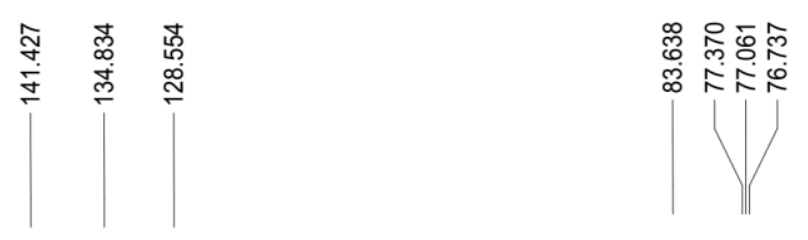

䍠是
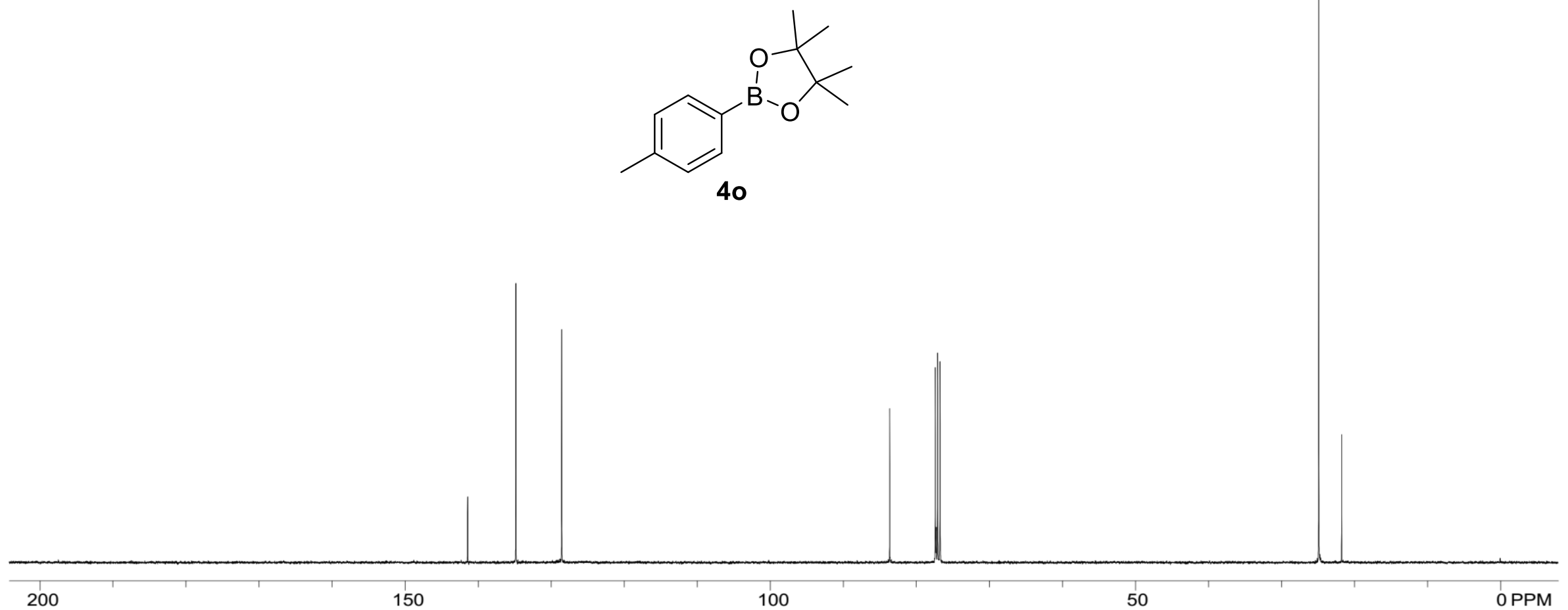


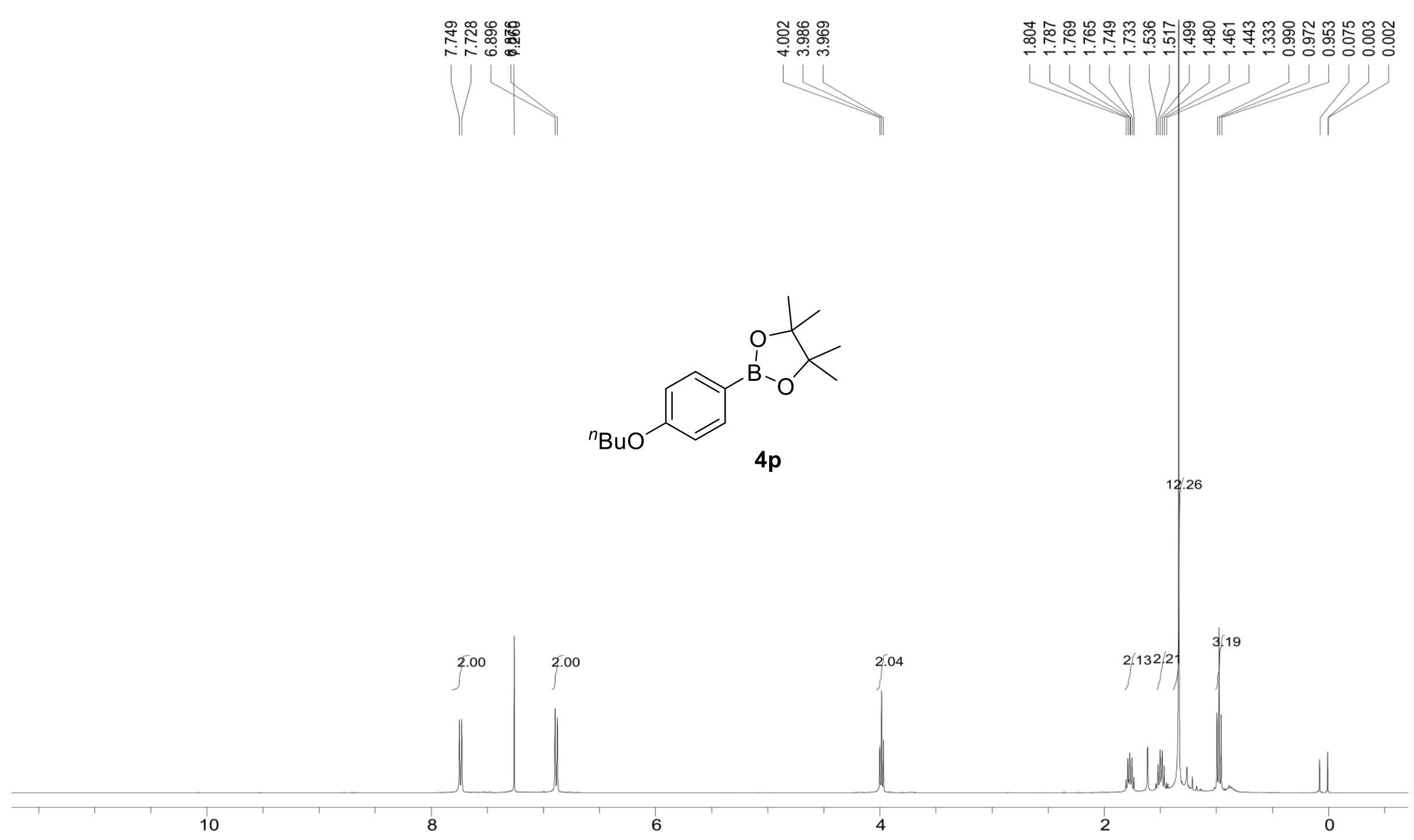




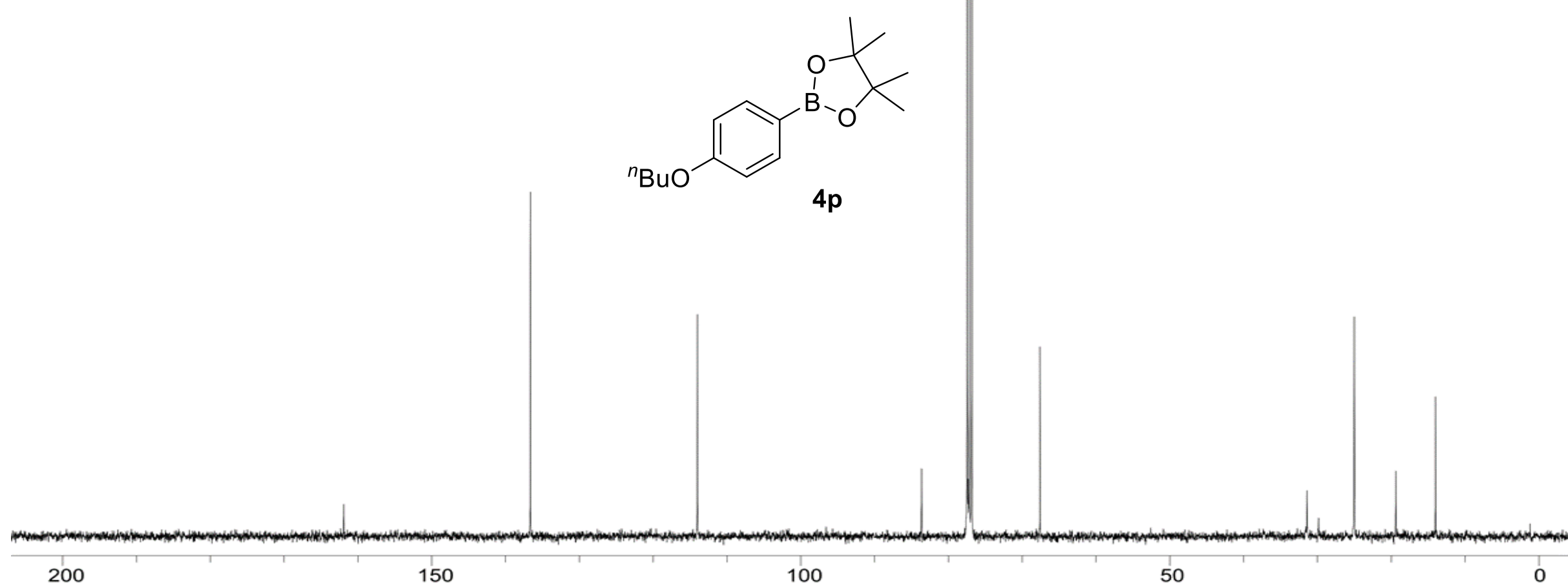




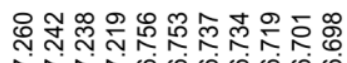

.

W
营

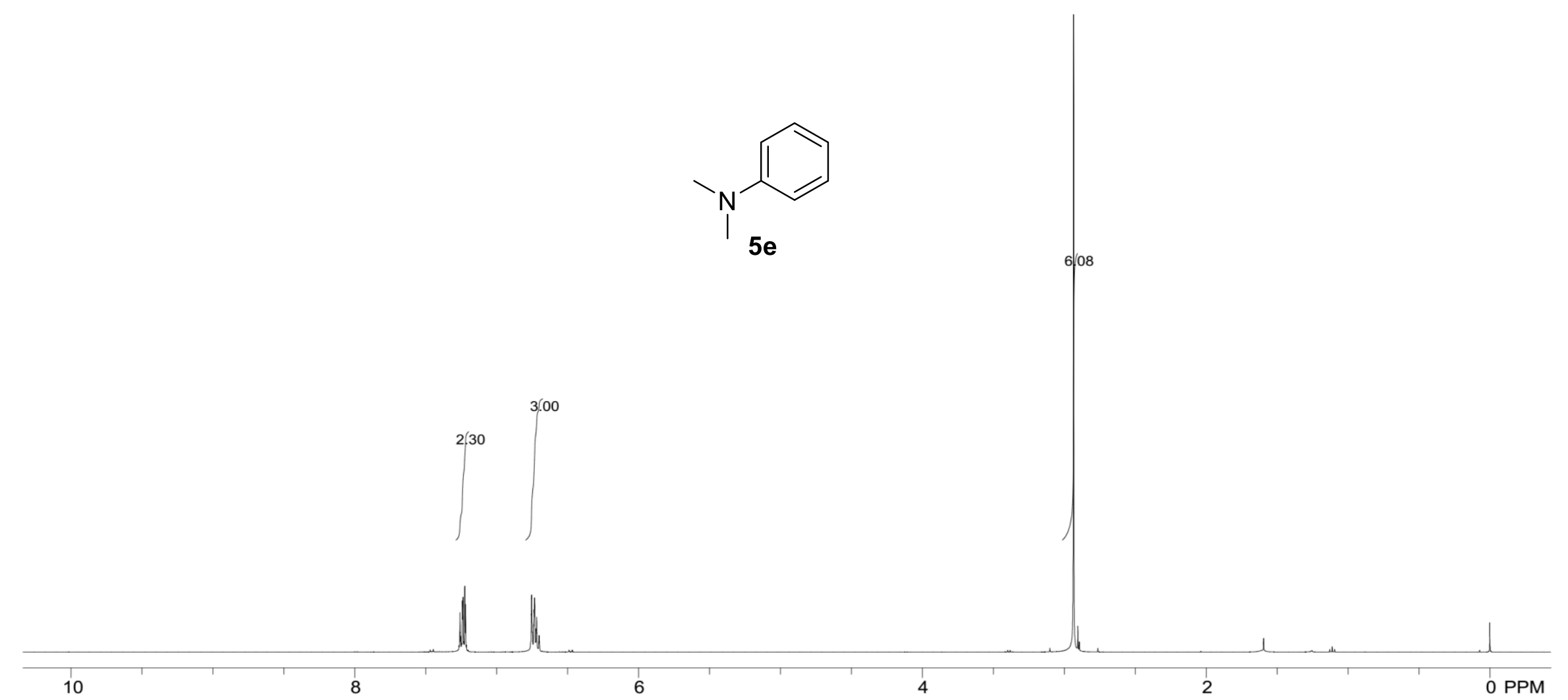



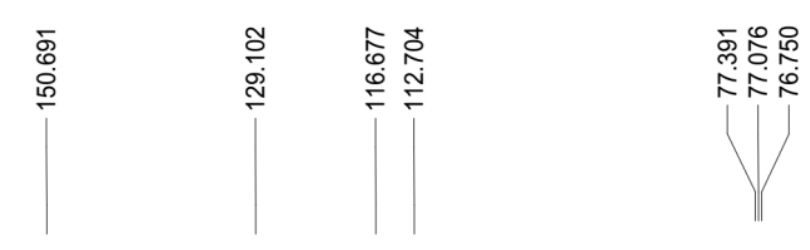

융
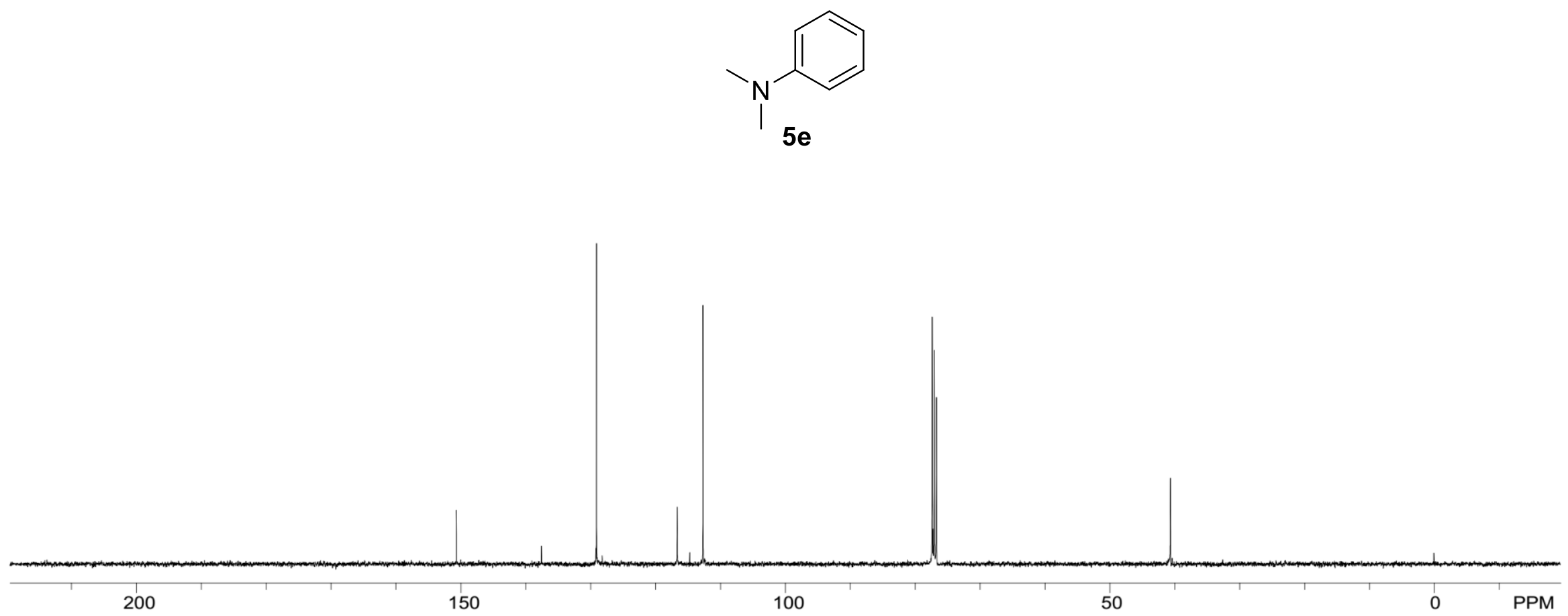


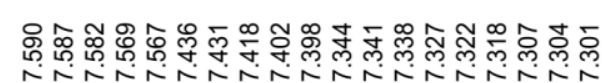

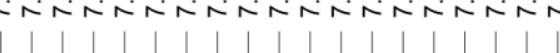

(n)

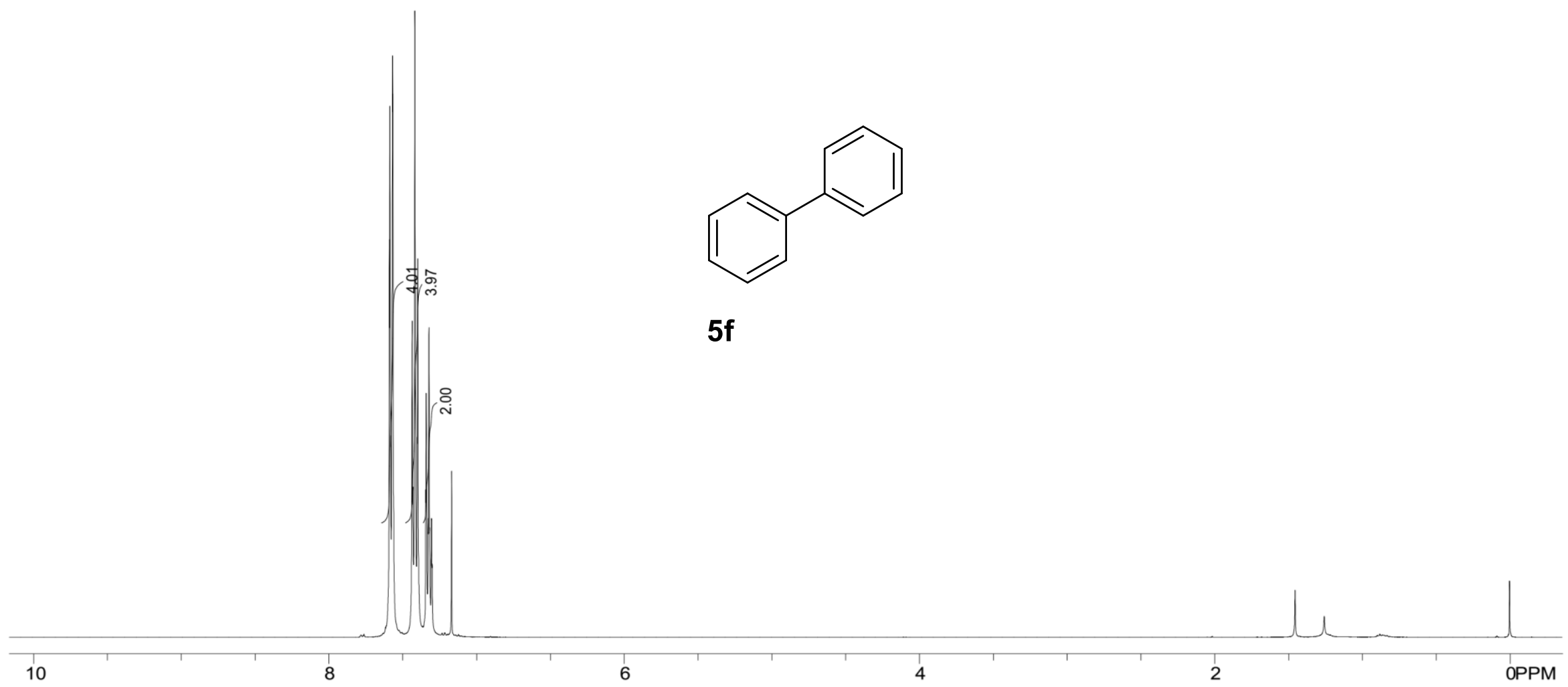




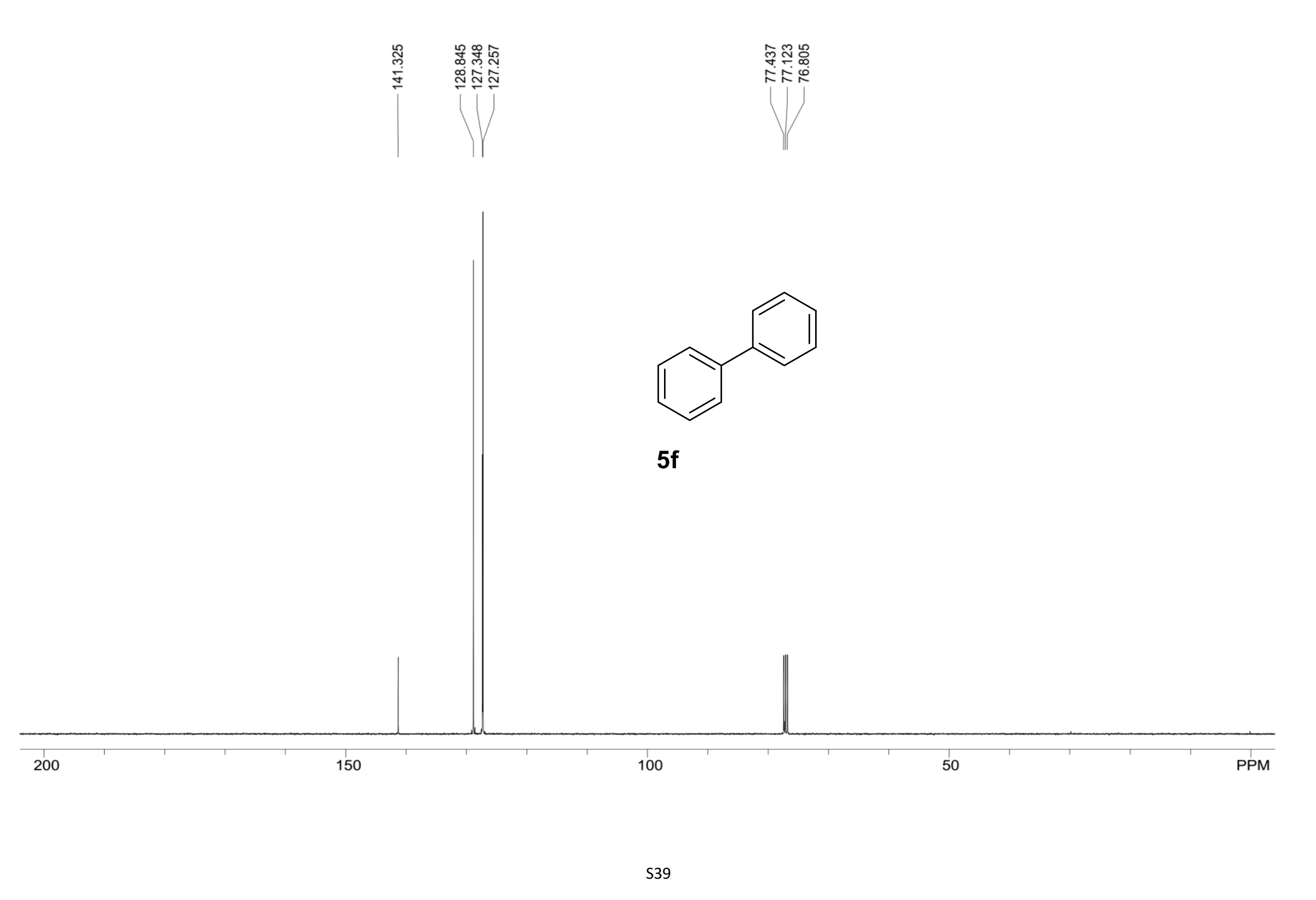




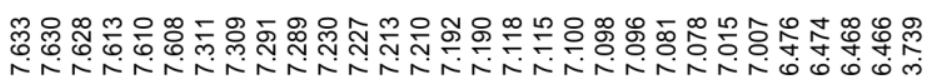

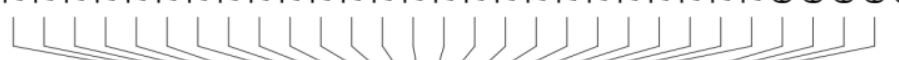

( I Miा

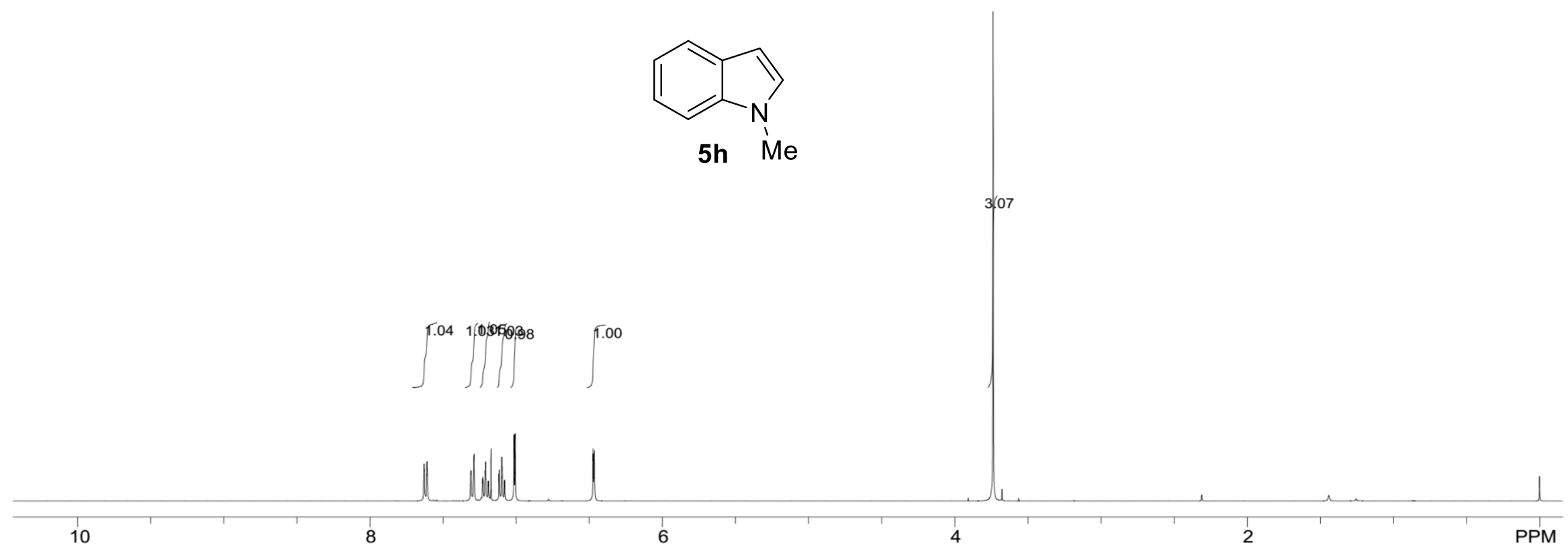



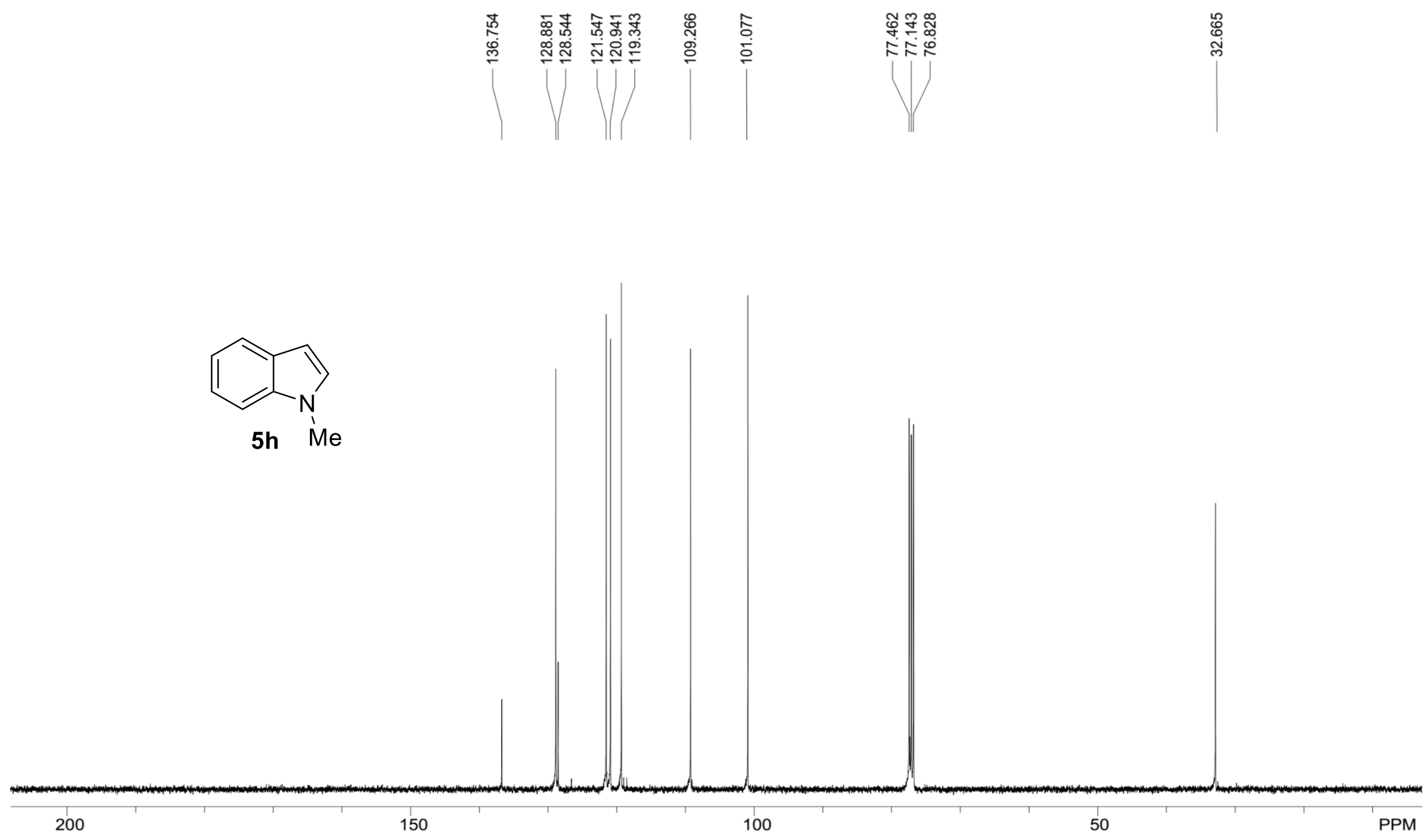


$$
\overline{1^{\circ}}
$$



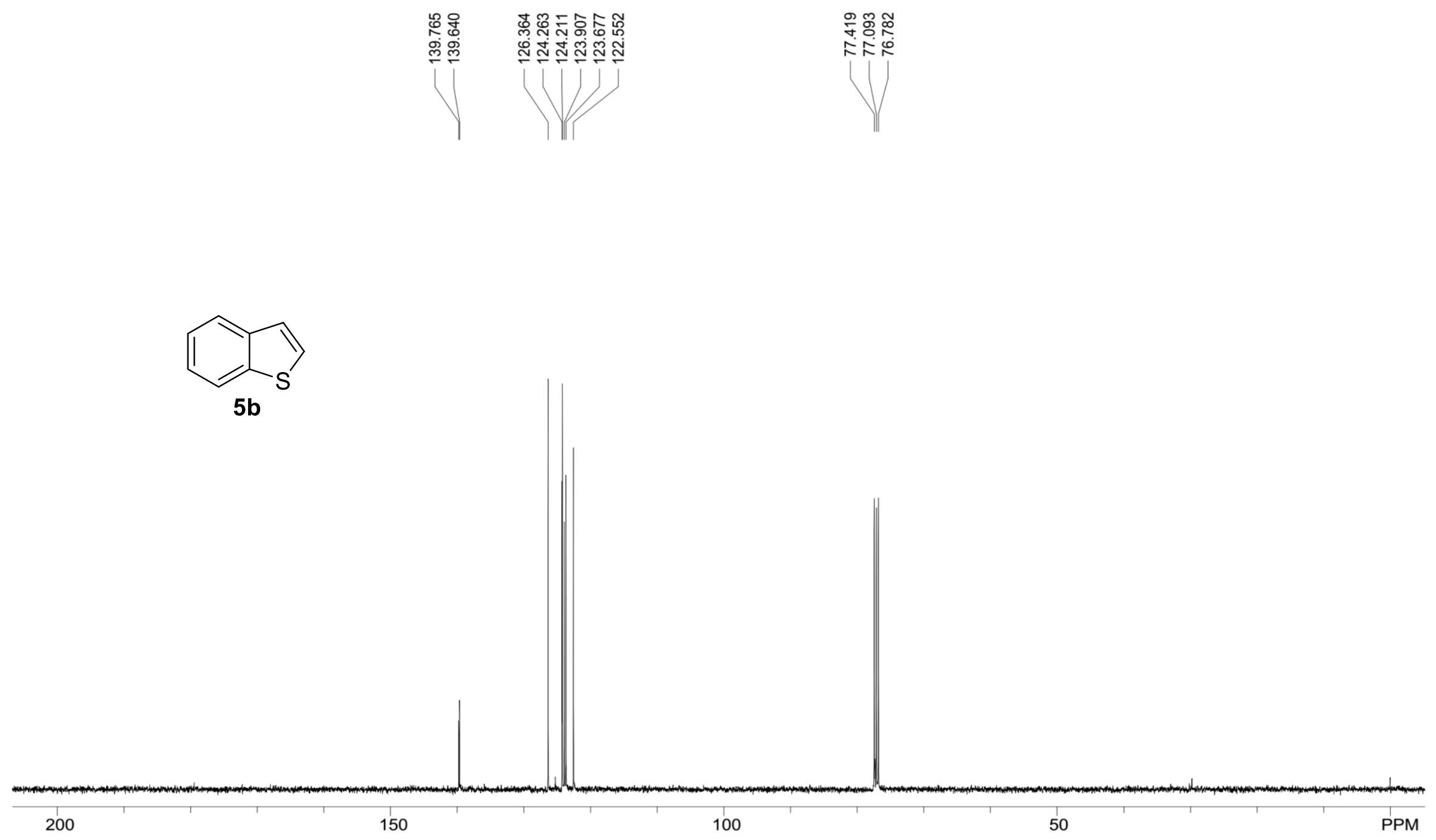


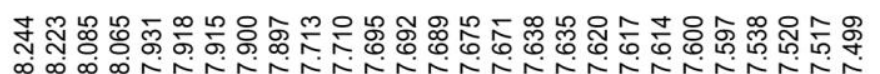

ب

[ \|\|\|\|

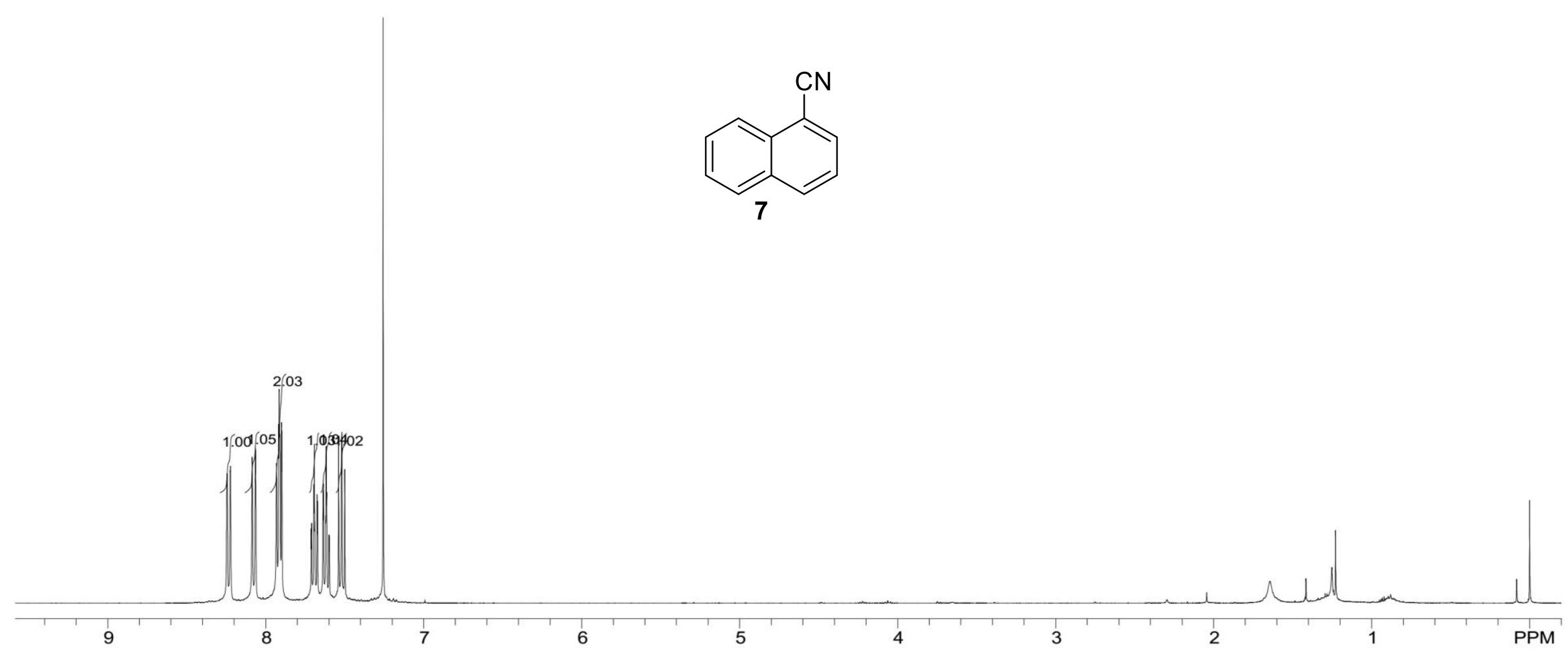




$$
\dot{j}
$$



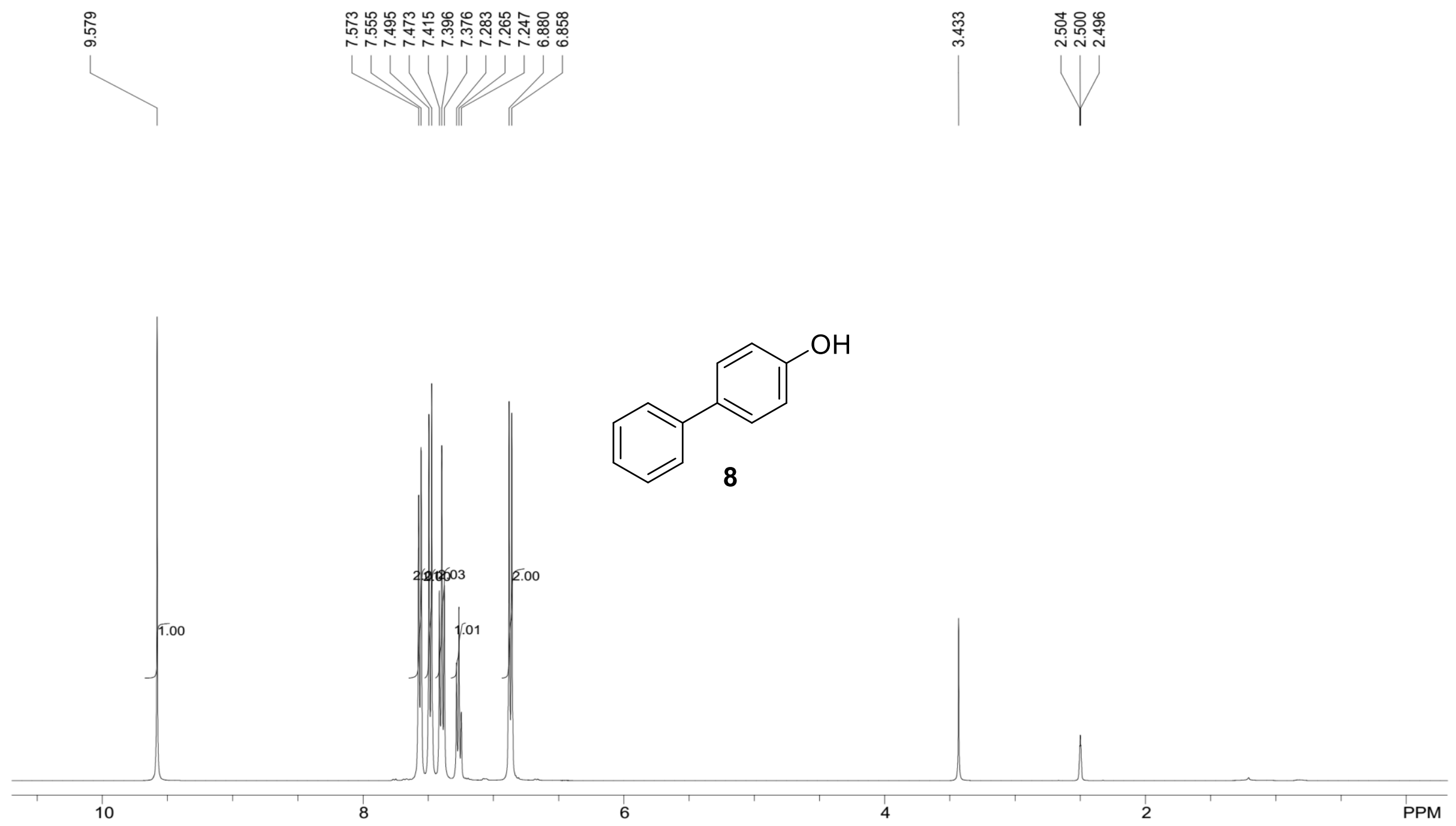


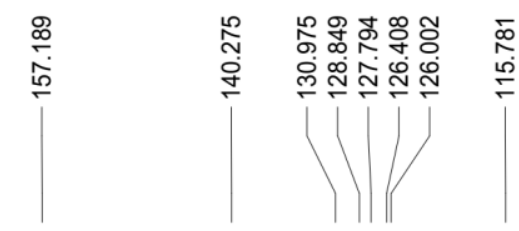

우유.

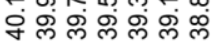

,

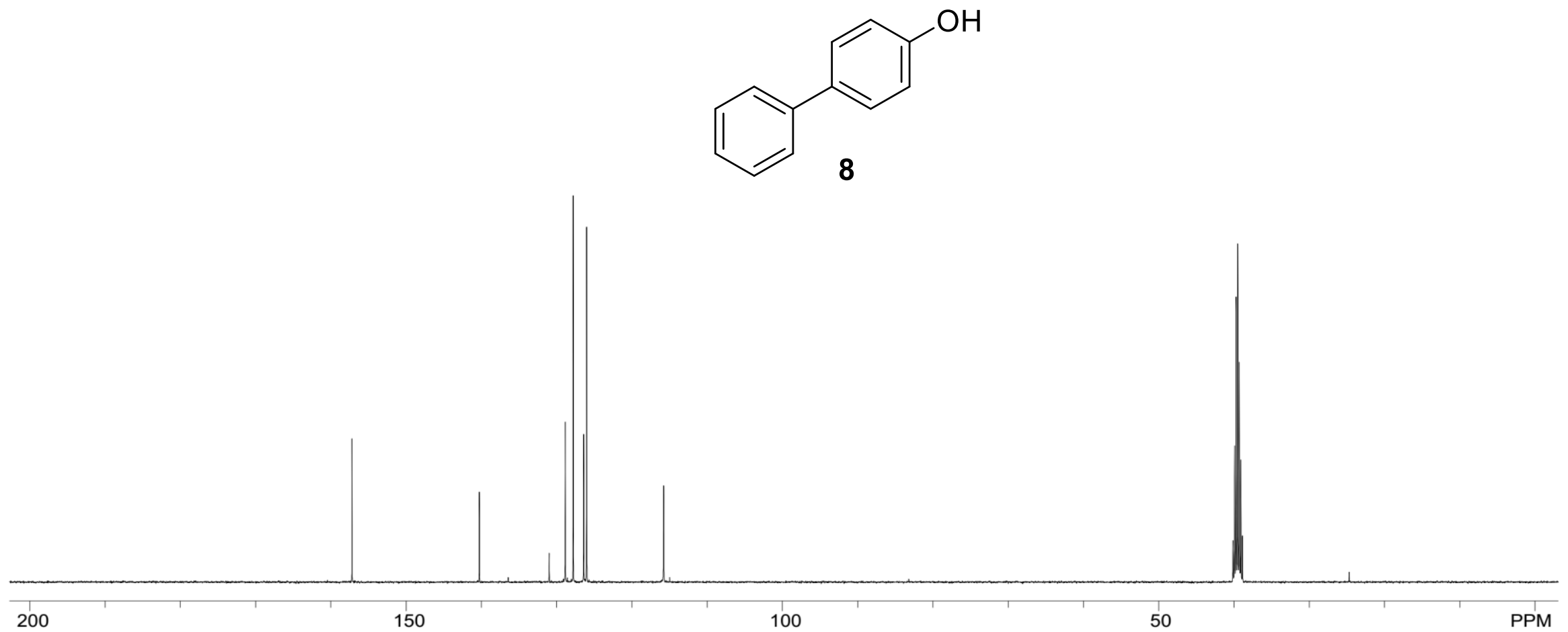

